\title{
CASE STUDY ON SEISMIC TUNNEL RESPONSE
}

By Stavroula Kontoe ${ }^{1}$, Lidija Zdravkovic ${ }^{1}$, David M. Potts ${ }^{1}$ and Christopher O. Menkiti ${ }^{2}$

${ }^{1}$ Imperial College, London

${ }^{2}$ Geotechnical Consulting Group

\section{Correspondence to:}

Stavroula Kontoe

Department of Civil and Environmental Engineering

Skempton Building

South Kensington Campus, London, SW7 2AZ

Tel: +44(0)20 7594 5996, Fax: +44(0)20 75945934

Email: stavroula.kontoe@imperial.ac.uk 


\begin{abstract}
:
This paper presents a case study of the Bolu highway twin tunnels that experienced a wide range of damage during the 1999 Duzce earthquake in Turkey. Attention is focused on a particular section of the left tunnel that was still under construction when the earthquake struck and that experienced extensive damage during the seismic event. Static and dynamic plane strain finite element (FE) analyses were undertaken to investigate the seismic tunnel response at two sections and to compare the results with the post-earthquake field observations. The predicted maximum total hoop stress during the earthquake exceeds the strength of shotcrete in the examined section. The occurrence of lining failure and the predicted failure mechanism compare very favourably with field observations. The results of the dynamic FE analyses are also compared with those obtain by simplified methodologies (i.e. two analytical elastic solutions and quasi-static elasto-plastic FE analyses). For this example, the quasistatic racking analysis gave thrust and bending moment distributions around the lining that differed significantly from those obtained from full dynamic analyses. However, the resulting hoop stress distributions were in reasonable agreement.
\end{abstract}

Key words: Bolu tunnels, Duzce earthquake, soil-structure-interaction, finite element analysis 


\subsection{Introduction}

Until recently, it was widely believed that underground structures are not particularly vulnerable to earthquakes. However, this perception changed after the severe damage and even collapse of a number of underground structures that occurred during recent earthquakes (e.g. the 1995 Kobe, Japan earthquake, the 1999 Chi-Chi, Taiwan earthquake and the 1999 Duzce, Turkey earthquake).

The present study considers the case of the Bolu highway twin tunnels that experienced a wide range of damage during the 1999 Duzce earthquake in Turkey. The Bolu tunnels establish a well-documented case, as there is information available regarding the ground conditions, the design of the tunnels, the ground motion and the earthquake induced damage. The focus in the present study is placed on a part of the Bolu tunnels that was still under construction when the earthquake struck and that suffered extensive damage.

The seismic response of circular tunnels has been the subject of a number of studies. Owen and Scoll (1981) suggest that the response of circular tunnels to seismic shaking can be described by the following types of deformation: axial compression or extension, longitudinal bending and ovaling. Clearly, to describe all three modes of tunnel deformation a three-dimensional model would be required. However, Penzien (2000), among others, suggests that the most critical deformation of a circular tunnel is the ovaling of the cross-section caused by shear waves propagating in planes perpendicular to the tunnel axis. Hence, a number of simplified methods have been developed to quantify the seismic ovaling effect on circular tunnels, which is commonly simulated as a two-dimensional plane strain condition. The so called "freefield deformation" approach ( e.g. St. John and Zahrah 1987) is based on the theory of wave propagation in an infinite, homogeneous, isotropic, elastic medium and it ignores any soil-structure interaction. Besides, there are various closed form solutions (e.g. Hoeg 1968 and Schwartz and Einstein 1980, Penzien 2000), based on the theory of an elastic beam on an elastic foundation, that consider the soil-structure-interaction (SSI) effects in a quasi-static way, ignoring though any inertial interaction effects. 
Both quasi-static and truly dynamic numerical modelling techniques (i.e. finite differences, finite element and boundary element methods) are also widely used to examine the seismic response of tunnels. An extensive review of the abovementioned methods can be found in Hashash et al (2001).

In the present study, dynamic finite element analyses are employed to investigate the seismic response of two sections of the Bolu tunnels. The results of the dynamic FE analyses are then compared with field observations and with results obtained by simplified methodologies (i.e. analytical elastic solutions and quasi-static elasto-plastic FE analyses).

\subsection{Construction details}

The tunnels of interest are part of the Trans-European Motorway that links Europe to the Middle East. They lie within the Gumusova-Gerede section, which is between Ankara and Istanbul, where the motorway exists as a series of viaducts, tunnels and embankments. The $23.7 \mathrm{~km}$ long Gumusova-Gerede section, which crosses the Bolu Mountain, is constructed in complex ground conditions and includes the $3.3 \mathrm{~km}$ long Bolu twin tunnels.

The construction of the Bolu twin tunnels started at the Asarsuyu (west) portal in 1993 and at the Elmalik (east) portal in 1994. The twin tunnels were constructed as four drives, two from each portal. The tunnel alignment is roughly " $\mathrm{S}$ " shaped in plan, with the majority of the tunnel running north-south (Figure 1). Their cross-sections range from $133 \mathrm{~m}^{2}$ to $260 \mathrm{~m}^{2}$ to accommodate the changing ground conditions and they are separated by a $50 \mathrm{~m}$ wide rock/soil pillar. The maximum overburden cover is $250 \mathrm{~m}$, with most of the cross-sections under a cover of $100-150 \mathrm{~m}$. The ground conditions along the tunnels alignment are highly variable, consisting of extremely tectonised and sheared mudstones, siltstones and limestones, with thick layers of stiff highly plastic fault gouge clay.

The initial design of the tunnels, based on the standard Austrian rock classification system, adopted the New Austrian Tunnelling Method (NATM). This technique is also known as the Sprayed Concrete Lining (SCL) method. With this 
design approach a flexible shotcrete lining was initially employed to provide temporary support after excavation, but allowing some controllable deformation. The final lining of cast in-situ concrete was subsequently installed at a convenient stage in the construction programme to complete the tunnel and provide long-term stability. The classic NATM system proved to be inadequate for tunnel sections through poor ground as large uncontrolled deformations and even partial collapse of the temporary lining were observed. As a consequence a thorough design review was instigated in 1998/1999, which included a more detailed site investigation and geotechnical characterisation of the ground conditions (Menkiti et al 2001b). Due to the highly variable ground conditions, the project was divided into various "design areas" each with an associated solution. The design solution that is relevant to the present study (as shown in Figure 2) applies to the worst ground conditions, namely thick zones of plastic fault gouge clay (see Figure 5). For such ground conditions two pilot tunnels were first constructed at the bench level and back-filled with reinforced concrete so as to serve as stiff abutments for further construction stages. The main tunnel was then advanced in three staggered headings. It should be noted that the bench pilot tunnels themselves are substantial structures with an external diameter of $5 \mathrm{~m}$, constructed by full face excavation and supported with shotcrete and light steel ribs in $1.1 \mathrm{~m}$ round lengths. An average progress rate of two rounds per day was achieved during the construction of the bench pilot tunnels. The primary shotcrete support $(40 \mathrm{~cm}$ thick) of the main tunnel was augmented with an additional $60-80 \mathrm{~cm}$ cast-in-situ concrete layer (intermediate lining) which provided stiff support close to the tunnel face. Ring closure of the main tunnel was achieved by invert construction at a short distance behind the face $(22 \mathrm{~m}$ to $35 \mathrm{~m})$. The inner lining was then cast. When the Duzce earthquake struck the Bolu region, on 12/11/1999, only about $2 / 3$ of the tunnel alignment had been completed.

\subsection{The 1999 Duzce earthquake and post-earthquake field observations}

In 1999, Turkey suffered two major earthquakes on the North Anatolian Fault Zone (NAFZ). First in August, the Kocaeli earthquake struck with a moment magnitude of $\mathrm{M}_{\mathrm{w}}=7.4$ and a bilateral rupture of at least $140 \mathrm{~km}$ length, extending from 
Gölcük to Melen Lake. Three months later (12/11/1999), a second earthquake, known as the Duzce earthquake, struck with a moment magnitude of $M_{w}=7.2$. The surface rupture associated with the second event also propagated bilaterally in an east-west direction, but was significantly smaller (40km) (Barka and Altunel, 2000). However, GPS studies and radar interferometry studies suggest that the sub-surface slip extended north-eastwards, beyond the eastern limits of the mapped surface rupture (shown as dotted lines in Figure 1) (Lettis and Barka 2000).

The Bolu tunnels did not suffer any damage during the first event. Conversely, due to the close proximity of the tunnels to the Duzce rupture, extensive damage in various sections of the tunnels was observed after the second event. The west portals of the Bolu tunnels are located within $3 \mathrm{~km}$ from the east tip of the Duzce rupture and within $20 \mathrm{~km}$ from the earthquake's epicenter. Ground motion records from the November event close to the project site and to the causative fault are available from the Duzce and the Bolu strong motion stations.

Due to the proximity of the project to the fault rupture, the ground motion at the tunnels was presumably influenced by near fault effects. Although the Bolu station motion is located at a distance of $18.3 \mathrm{~km}$ from the surface rupture, it has some features which are characteristic of near-field motions. In particular, Akkar and Gülkan (2002) identified a strong pulse fling in the E-W Bolu accelerogram. Furthermore, Sucuoğlu (2002) suggests that the short duration of the strong motion at the Duzce station compared to Bolu indicates that the Bolu station was in the forward directivity of the ruptured segment of the fault. The Bolu station is the closest recording station to the Bolu Tunnels and its digital seismograph is mounted on an isolated concrete pillar founded $2 \mathrm{~m}$ into the sub-soil, reflecting the ground motion of a soil layer with Vs $=580 \mathrm{~m} / \mathrm{s}$. It probably also very closely reflects the bedrock (sandstone layer with $\mathrm{Vs}=1178 \mathrm{~m} / \mathrm{s}$ at a depth of $6.6 \mathrm{~m}$ ) ground motions. Taking also into account the bilateral mechanism of the rupture and the relative positions of the stations with respect to the project and the rupture (see Figure 1), it can be concluded that the ground motion of the Bolu station is the most representative for the case study. Since the causative fault generally runs in an east-west direction, the E-W and $\mathrm{N}-\mathrm{S}$ accelerograms represent the fault parallel and normal components of the motion 
respectively. Furthermore, as one would expect for a lateral strike-slip fault, the vertical component of the motion is significantly smaller $(\mathrm{PGA}=0.2 \mathrm{~g})$.

Due to the Duzce earthquake the Bolu tunnels experienced a wide range of damage, depending on the ground conditions, the construction method and the construction phase. Completed tunnels performed well, but in poor ground partly completed tunnels, where only the initial support had been installed, suffered severe damage and even collapse. Menkiti et al (2001a) and O'Rourke et al (2001) provide a detailed description of the tunnels' performance during the earthquake. The focus of this paper is a zone of poor fault gouge clay where collapses occurred over a length of $30 \mathrm{~m}$ in both bench pilot tunnels (BPTs) of the Asarsuyu left drive (see Figure 4).

The BPTs were of $5 \mathrm{~m}$ external diameter and provide a useful example for backanalysis due to the completeness of the available information. The BPTs were in pristine condition before the earthquake, having been constructed between $16^{\text {th }}$ October and 12 November 1999, with the Duzce earthquake occurring on the evening of $12^{\text {th }}$ November 1999. When the Duzce earthquake struck, the BPTs of the Asarsuyu left tunnel had not yet been back-filled with concrete and were only supported by $30 \mathrm{~cm}$ thick shotcrete and HEB 100 steel ribs set at $1.1 \mathrm{~m}$ longitudinal spacing. Figure 3a shows a picture of the partially collapsed left bench pilot tunnel (LBPT) during post-earthquake repairs. The collapse is described as partial in the sense that although the lining was very heavily damaged and deformed, it was not breached such that the tunnel became in-filled with surrounding ground. Tunnel repairs comprised reexcavating the damaged tunnel together with a surrounding annulus of soil, followed by construction of a new pilot tunnel in the space created. Prior to commencement of repairs, the damaged tunnel was carefully inspected and then stabilized by backfilling it with foam concrete. This also served to preserve the structure of the damaged tunnel, as shown in Figure 3, allowing further study during re-excavation. Excessive deformation of the cross-section induced by the earthquake involved crushing of the shotcrete and buckling of the steel ribs at shoulder and knee locations and invert uplift up to $0.5 \mathrm{~m}-1.0 \mathrm{~m}$. At some locations the buckled steel ribs shortened by up to 0.3 $0.4 \mathrm{~m}$. Figure 4 shows a plan view of the Asarsuyu left tunnel progress when the earthquake struck. The bench pilot tunnels have a center-to-center separation of 19.0 
$\mathrm{m}$, and were being progressed with the left BPT leading the right one. The postearthquake investigations showed several interesting features of damage:

1. Damage was limited to the zone of fault gouge clay.

2. Severe damage and partial collapses were limited to the zone in which the two BPTs overlap.

3. Damage was generally found to be more pronounced in the LBPT.

4. Interestingly, the leading portion of the LBPT in the same material (i.e. fault gouge clay) did not collapse.

The present study employs two dimensional dynamic FE analyses to examine the soilstructure interaction response at Sections A-B and C-D in Figure 4, with the objective of explaining some of the observed damage.

\subsection{Ground conditions}

As noted previously, the design reassessment in 1998/1999 included a detailed site investigation and geotechnical characterisation of the ground conditions. An exploratory pilot tunnel was driven from each portal, which allowed detailed characterisation of the ground conditions ahead of the main drives. Furthermore, the ground investigation included sub-surface boreholes drilled from the pilot tunnels as well as surface boreholes. The derived ground conditions for cross-sections $\mathrm{AB}$ and $\mathrm{CD}$ are presented in Figure 5. The water table was established at a depth of $62 \mathrm{~m}$ below the ground surface.

Table 1 summarizes a description of the various geotechnical units and their index properties. The strength properties (the angle of shearing resistance $\varphi^{\prime}$, the cohesion $\mathrm{c}^{\prime}$ and the undrained strength $\mathrm{Su}$ ) and the estimated maximum elastic shear modulus $\left(\mathrm{G}_{\max }\right)$ values are listed in Table 2.

The strength properties of the two clay layers and the metasediments are based on laboratory shear strength tests, as reported by Menkiti et al (2001a), while the calcareous sandstone and the sandstone overlaying the bedrock were assumed to have the same drained strength properties as the metasediments. Moreover, the estimated 
maximum shear modulus $\left(\mathrm{G}_{\max }\right)$ values of the two clay layers and metasediments are based on pressuremeter tests, as reported by Menkiti et al (2001a), while the $G_{\max }$ values of the two sandstones are based on the values published by O'Rourke et al (2001).

\subsection{Description of the numerical model}

Plane strain analyses of the Bolu bench pilot tunnels (BPTs) were undertaken for the cross sections $\mathrm{AB}$ (chainage 62+850) and $\mathrm{CD}$ (chainage 62+870) with the finite element program ICFEP (Potts and Zdravkovic 1999). Figure 6 illustrates the finite element mesh used in the analyses of the cross-section $\mathrm{AB}$, which consists of 5574 8-noded quadrilateral solid elements and 62 3-noded beam elements. The FE mesh models the ground stratigraphy down to the interface of the sandstone with the quartzic rock (see Figure 5), which is a very stiff formation. The two-surface kinematic hardening model (M2-SKH) of Grammatikopoulou et al (2006) was employed to simulate the soil behavior in all the FE analyses. The M2-SKH model is an extension of the Modified Cam Clay (MCC) model, as it introduces a small kinematic yield surface within the MCC bounding surface and can therefore reproduce soil hysteretic behaviour, which is important for dynamic analysis. The model requires in total 7 parameters and their adopted values are given in the Appendix.

To accurately represent the wave transmission through the finite element mesh, it is necessary to ensure that the element size is small relative to the transmitted wavelengths. Accordingly, the element side length $(\Delta \mathrm{l})$ was chosen based on the recommendation by Kuhlemeyer and Lysmer (1973) that:

$$
\Delta \mathrm{l} \leq \frac{\mathrm{V}_{\mathrm{S}_{\min }}}{8 \mathrm{f}_{\max }}
$$

where $\mathrm{V}_{\mathrm{Smin}}$ is the lowest shear wave velocity that is of interest in the simulation and $f_{\max }$ is the highest frequency of the input wave. Since in nonlinear problems the soil stiffness changes during the analysis, an estimate of the minimum shear wave velocity for each layer was obtained by undertaking equivalent linear analyses with the 
software EERA (Bardet et al 2000), while the highest frequency was taken equal to $15 \mathrm{~Hz}$. The Fourier amplitude values of the uncorrected Bolu record in the high frequency limit (e.g. greater than $10 \mathrm{~Hz}$ ) are almost zero and thus the choice of the maximum cut-off frequency does not significantly affect the accuracy of the process. The adopted shear stiffness-shear strain and damping-shear strain curves are presented in the Appendix.

As previously mentioned various analytical studies suggest that the most critical deformation of a circular tunnel is the ovaling of the transverse cross-section caused by shear waves propagating in planes perpendicular to the tunnel's axis. The alignment of the Bolu tunnels is approximately perpendicular to the fault rupture. Therefore, the E-W component of the ground motion, which is parallel to the fault rupture, is the one responsible for the shear deformation of the tunnels' transverse cross-section and was employed in all dynamic FE analyses.

As shown in Figure 5 the bedrock is located at a considerable depth from the ground surface (193m and $185 \mathrm{~m}$ for chainages $62+850$ and $62+870$ respectively). Since there is no bedrock strong motion record in the vicinity of the tunnels, the surface accelerogram was scaled to $70 \%$ to account for strong motion attenuation with depth. The scaling factor (i.e. 0.7) adopted in this study is in agreement with the recommendations of the Federal Highway Agency (FHWA, 2000) for depths of more than $30 \mathrm{~m}$ and is an upper bound for data collected from down-hole arrays (e.g. Archuleta et al, 2000). Deconvolution analyses, assuming linear elastic soil behaviour, were also performed both for the site of the Bolu station and for the site of the BPTs, showing reduction factors of 0.85 and 0.5 respectively. However, since the bedrock at the two sites differs, it was decided to finally adopt the FHWA, (2000) recommendation of 0.7 which is close to the average value of the two deconvolution analyses. In any case there is a degree of uncertainty in this approach which cannot be avoided. A fourth order band-pass Butterworth filter was used to remove the extreme low (below $0.1 \mathrm{~Hz}$ ) and the high frequency components (above 15Hz) of the record. Furthermore, there is no need to use the full duration of the seismic motion, as the important shaking is limited to the time interval of $5 \mathrm{sec}-40 \mathrm{sec}$. Figure 7 illustrates the processed and scaled acceleration time history that was employed in all the dynamic analyses, and the corresponding Fourier spectrum. The peak value of the input 
acceleration time history is $0.57 \mathrm{~g}\left(5.61 \mathrm{~m} / \mathrm{sec}^{2}\right)$ and it occurs approximately $5.8 \mathrm{sec}$ after the onset of the excitation.

The width of the mesh and the lateral boundary conditions should be such that free-field conditions (i.e. one-dimensional soil response) occur near to the lateral boundaries of the mesh. After conducting a series of numerical tests (for details see Kontoe, 2006), comparing the far-field 2D (i.e. with tunnels) response with the one obtained from a 1D FE analysis (without any tunnels), the width of the mesh was selected to be $219 \mathrm{~m}$ and the tied degrees of freedom (TDOF) boundary condition was applied along the vertical sides of the mesh. This boundary condition constrains nodes of the same elevation on the two side boundaries to deform identically. In Kontoe (2006) two more boundary conditions were examined for the lateral sides of the mesh: the standard viscous boundary of Lysmer and Kuhlemeyer (1969) and the domain reduction method in conjunction with the standard viscous boundary (Bielak et al 2003, Kontoe et al 2008b). The former method failed to reproduce the free-field response and led to a serious underestimation of the response in the near field for a mesh width of $219 \mathrm{~m}$. The latter method, which allows quantification of any wave reflection from the lateral boundaries, showed that there were no significant wave reflections from the lateral boundaries. Therefore it was concluded that the simple tied degrees of freedom boundary condition could be used as it can successfully reproduce the free-field response. The acceleration time history of Figure 7 was applied incrementally in the horizontal direction to all nodes along the bottom boundary of the FE model (i.e. along the bedrock-sandstone interface), while the corresponding vertical displacements were restricted. The time integration was performed with the Generalised- $\alpha$ method (Chung and Hulbert 1993) which is an unconditionally stable, second order accurate scheme with controllable algorithmic dissipation (Kontoe et al 2008a). After conducting a series of numerical tests comparing 1D FE analyses with equivalent linear EERA analyses the time step was selected to be $\Delta \mathrm{t}=0.01 \mathrm{sec}$.

\subsection{Modelling of construction sequence}

When the earthquake struck, considerable static stresses were acting on the tunnel linings due to the overburden pressure and the construction process. Hence, 
prior to all 2D dynamic analyses presented in this study, a static analysis was undertaken to establish the initial stresses acting on the lining. During the static analysis displacements were restricted in both directions along the bottom mesh boundary and horizontal displacements were restricted along the side boundaries. Undrained behaviour was assumed for the clay units and drained conditions were assumed for the rock layers.

As noted previously when the earthquake struck the BPTs were under construction and they were therefore only supported by a $30 \mathrm{~cm}$ thick preliminary shotcrete lining with HEB 100 steel ribs set at $1.1 \mathrm{~m}$ longitudinal spacing. While in a 3-dimensional model it is sensible to model the steel ribs, in plane strain analyses the moment of inertia contribution from the steel ribs is very small compared to that provided by the shotcrete. Therefore the steel ribs were ignored in all the analyses. It should also be noted that at the time of the earthquake, the shotcrete had not yet developed its full operational strength. Based on measured strength for the insitu shotcrete development curves, the estimated strength and stiffness properties of the tunnel linings at the instant of the earthquake at chainage $62+850$ are listed in Tables 3 and 4 respectively.

The lining was modelled with beam elements, without using any interface elements, and for all the analyses it was assumed to behave in a linear elastic manner. The beam elements were generated within the mesh but deactivated at the beginning of the analysis (i.e. in increment 0 which corresponds to the mesh generation stage). The tunnel construction was modelled using the convergence-confinement method which is described in detail by Potts and Zdravkovic (2001). Starting from a greenfield profile, the excavation of the tunnels causes stress relief in the ground. To model this excavation process, equivalent nodal forces along the tunnel boundary, which represent the stresses exerted by the excavated soil, are calculated and are then removed over several increments of the analysis. During this process the elements representing the excavated soil are non active. These forces are assumed to vary linearly with the number of increments over which the excavation is to take place. The excavation of the two BPTs was performed simultaneously in ten increments and during the analysis the tunnels' linings were activated, at the increment corresponding to required stress relaxation, prior to the completion of excavation. In particular the 
LBPT lining was constructed at $50 \%$ of stress relaxation (i.e. increment 5), whereas the RBPT lining was constructed at $60 \%$ of stress relaxation (i.e. increment 6). The higher value of stress relaxation assumed for the RBPT was used to account for the fact that this tunnel was constructed after the LBPT and consequently in de-stressed ground. For both tunnels an initial Young's modulus of 5GPa was assigned which was increased to $28 \mathrm{GPa}$ and to $21 \mathrm{GPa}$ for the LBPT and RBPT linings (see ) respectively after the completion of excavation (i.e. increment 11). All the geometrical and material properties of the BPTs linings are summarized in Table 5 and the coefficient of earth pressure at rest profile is given in the Appendix (Figure A.1).

The static stresses acting on the tunnels' lining caused an elliptical deformed shape, which was slightly more pronounced in the RBPT. The amount by which the tunnels deformed is summarized in Table 6. Measurements from monitoring the exploratory pilot tunnel in a flyschoid clay (not at the sections considered herein) reported by Menkiti et al (2001b) indicate a horizontal convergence of $15 \mathrm{~mm}-25 \mathrm{~mm}$, which is lower than the FE predictions of Table 6.. However, it is also reported that the exploratory pilot tunnel experienced much larger movements in the fault gouge clay. Furthermore, measurements from a completed section of the left tunnel (main tunnel) in the gouge clay show a horizontal diametral convergence of the BPT concrete beams of $0.9 \%$ (Menkiti et al, 2001b). Therefore, the FE results are generally in good agreement with the observed static behaviour of the tunnels. The FE analysis also indicates that the RBPT, which was constructed at $60 \%$ stress relaxation but is more flexible than the LBPT (see ), experienced larger deformations. Figure 8 shows the accumulated thrust (compression positive), bending moment and maximum hoop stress distribution in the beam elements around the tunnels' lining. The maximum hoop stress distribution corresponding to the hoop stress at the extreme fibre of the lining reflects the combined effect of the compressive thrust $(\mathrm{T})$ and bending moment (M) and it was calculated as follows:

$$
\sigma_{H}=\frac{T}{A}+\frac{|M| y}{I}
$$

where $y$ is the distance from the neutral axis to the extreme fibre of the lining crosssection and $\mathrm{A}$ is the area per unit width of the lining cross-section. 
The thrust distribution is more or less uniform around the tunnel linings, while the bending moment values are quite low and show a fluctuation around the lining. Furthermore, the thrust and hoop stress distribution indicate that the LBPT attracted higher loads than the RBPT. Menkiti et al (2001b), based on the performance of the exploratory tunnel, estimated the immediate ground loads as being $40-65 \%$ of the overburden, which corresponds to hoop stresses of $7450-12120 \mathrm{kPa}$ in the tunnels' lining. The predicted hoop stresses for the RBPT lie within this range, while the ones for the LBPT are marginally above the upper limit of this range. Figure 9 presents contours of the pore water pressure distribution in the vicinity of the tunnels at the end of the static analysis. The FE results show that the excavation process causes the generation of pore water suctions. The contours of this tensile pressure are concentrically aligned around the tunnels and they gradually decay with distance, so that a compressive pore pressure is recovered at a distance from the tunnel linings approximately equal to $\mathrm{D} / 2$ (i.e. $\mathrm{D}$ is the tunnel diameter).

\subsection{D nonlinear dynamic analyses}

Once the static stresses acting on the tunnel linings were established, dynamic analyses at chainages $62+850$ and $62+870$ were undertaken assuming that all materials behaved in an undrained manner.

\subsubsection{Chainage $62+850$}

Figure 10 compares the maximum shear strain profiles (caused only by the dynamic excitation) at various distances $x$ from the axis of symmetry of the $2 \mathrm{D} \mathrm{FE}$ model (i.e. $\mathrm{x}=0.0 \mathrm{~m}, 13.0 \mathrm{~m}$ and $50.0 \mathrm{~m}$ ) with the response of the corresponding $1 \mathrm{D} \mathrm{FE}$ model. It appears that the free-field response is recovered at a distance $\mathrm{x}=50.0 \mathrm{~m}$, as the maximum shear strain profiles agrees well with the 1D results. Furthermore, the response at the level of the tunnels (the centre of the tunnels is at $\mathrm{z}=160.0 \mathrm{~m}$ ) is significantly de-amplified with respect to the free-field response at a distance $\mathrm{x}=13.0 \mathrm{~m}$, while it is amplified in the pillar (i.e. $\mathrm{x}=0.0 \mathrm{~m}$ ).

The ovaling tunnel deformation suggested by various analytical studies was verified by the FE analysis. Figure 11 illustrates an enlarged view of the deformed 
mesh shortly after the peak of the excitation (i.e. at $t=8.0 \mathrm{sec}$ ). The ovaling deformation is evident in both BPTs and it implies a stress concentration at the shoulder and knee locations of the lining. Figure 12 illustrates contours of deviatoric stress $(J)$ in the vicinity of the tunnels (i.e. for the area indicated in Figure 11) at various instances before and after the peak of the earthquake (i.e. at $\mathrm{t}=5.0,6.0,7.0$ and $8.0 \mathrm{sec}$ ). Initially (i.e. at $\mathrm{t}=5.0$ ) the stress contours have an almost vertical distribution, later they gradually concentrate around the shoulder and knee locations of the linings. Interestingly, shear planes at $45^{\circ}$ seem to form in the pillar at $t=8.0 \mathrm{sec}$. Figure 13 presents the mobilised shear strength ratio (i.e. the ratio of the mobilised over the available strength) distribution in the soil along the perimeter of the two BPTs for $\mathrm{t}=5.0 \mathrm{sec}$ and for $\mathrm{t}=10.0 \mathrm{sec}$. While the maximum mobilised strength ratio at $\mathrm{t}=5.0 \mathrm{sec}$ is only 0.15 , it reaches a value of 0.37 in the RBPT after the peak of the earthquake (i.e. $\mathrm{t}=10.0 \mathrm{sec})$. In any case it was observed that the mobilised strength ratio in the ground around both BPTs was well below 1 throughout the analysis.

Figure 14 presents the accumulated pore water pressure and shear strain time histories recorded at two integration points $E(x=9.1 \mathrm{~m}, \mathrm{z}=157.4 \mathrm{~m})$ and $\mathrm{F}(\mathrm{x}=-9.9 \mathrm{~m}$, $\mathrm{z}=157.4 \mathrm{~m}$ ) adjacent to the crowns of the LBPT and the RBPT respectively. As discussed in the previous section, the excavation process caused the generation of pore water suction around the tunnel linings. During the first seconds of the earthquake, the tensile pore pressure is maintained around both tunnels, but approximately at the peak of the input excitation (see Figure 7a) an abrupt jump is observed in Figure 14a, which results in a compressive pore pressure. Subsequently, the compressive pore pressure continues to build up for a few more seconds (approximately until $\mathrm{t}=10.0 \mathrm{sec}$ ) and then stabilizes. It should be noted that for both tunnels these stabilised values are lower than the prior to construction hydrostatic pore pressure at the crown level (i.e. $936.0 \mathrm{kPa}$ ). Furthermore the intense period of the shaking generates significant permanent strains. The maximum shear strain adjacent to the crown is $0.52 \%$ and $0.46 \%$ for the LBPT and the RBPT respectively. These values are more than twice the maximum free-field shear strain at the same level (i.e. at $\mathrm{z}=157.4 \mathrm{~m}$ ) which is $0.19 \%$ (see Figure 10 ).

Figure 15 shows the accumulated thrust (compression positive), bending moment and maximum hoop stress distribution, due to the combined effects of static 
and dynamic loading, in the beam elements around the BPTs' lining at $\mathrm{t}=10.0 \mathrm{sec}$. In all three plots the distribution is highly non-uniform around the tunnel linings and the maxima of the thrust, bending moment and maximum hoop stress occur at shoulder and knee locations (i.e. $\theta=137^{\circ}$ and $317^{\circ}$ respectively). This is in exact agreement with the post-earthquake field observations at the collapsed section of the LBPT, which showed crushing of shotcrete and buckling of the steel ribs at shoulder $\left(\theta=137^{\circ}\right)$ and knee $\left(\theta=317^{\circ}\right)$ locations of the lining (see Figure 3 ). Note that the photograph in Figure 3 shows the view looking south. The plots in Figures 8, 12 and 14 show the view looking North as indicated in section lines AB and CD in Figure 4. In Figure 14, the hoop stresses at $\theta=137^{\circ}, 317^{\circ}$ are approximately three times larger than the corresponding static stresses in Figure 8, while in other locations the stresses are on average two times larger. The thrust and bending moment time histories at $\theta=137^{\circ}$ of both BPTs are presented in Figure 16. In both tunnels, the axial forces start from an initial value, induced by the static loading, and during the most intense period of shaking they significantly increase. In a similar fashion to the pore pressure time histories (see Figure 14), when the shaking intensity reduces the loads stabilise. While the thrust developed in the RBPT is initially lower than that in the LBPT, during the intense period of the shaking the thrust curves of the two BPTs become indistinguishable. While the bending moment variations start from a very small initial value, they significantly increase during the intense period of the earthquake and finally stabilize to a relatively large value. It should be noted that the maximum and stabilised values of bending moment in the RBPT are considerably lower than those observed in the LBPT. Overall, the dynamic analysis results indicate that the LBPT attracted higher loads than the RBPT. This is in agreement with post-earthquake field observations suggesting that the LBPT experienced more severe damage than the RBPT.

Table 7 summarizes the values of maximum hoop stress recorded at shoulder and knee locations (i.e. at $\theta=137^{\circ}, 317^{\circ}$ ) of the lining due to static and dynamic loading. The predicted maximum total hoop stresses exceed the strength of the shotcrete in both tunnels, which is $40 \mathrm{MPa}$ and $30 \mathrm{MPa}$ for the LBPT and RBPT respectively (see ), and they thus match favourably with the observed failure. However, it should be noted that the beam elements were assumed to behave as a linear elastic material. Therefore the present FE analysis cannot actually model the 
cracking of the lining and thus the predicted loads may differ to some extent from the loads that were actually acting on it.

\subsubsection{Chainage $62+870$}

As previously discussed, the Duzce earthquake caused striking damage to the BPTs in the area that the two tunnels overlapped, but the leading portion of the LBPT in the same material (i.e. fault gouge clay) did not suffer extensive damage (see Figure 4). Two possible explanations were identified:

1. During the seismic event the BPTs presumably interacted, as the pillar between the tunnels is small. Thus, wave reflections in the pillar possibly caused amplification of the ground motion in the area where the BPTs overlap.

2. The different stratigraphy of the cross section $C D$ (i.e. at chainage $62+870$ ) resulted in lower seismic loads at the LBPT at this location compared to those acting on it at the cross section $\mathrm{AB}$ (i.e. chainage $62+850$ ).

To investigate these two postulations, two sets of analyses were undertaken. In the first set of analyses, denoted in future discussions as 1BPT-AB, the analyses of the cross-section $\mathrm{AB}$ at chainage $62+850$ (denoted in future discussions as $2 \mathrm{BPTs}-\mathrm{AB}$ ) were simply repeated without the RBPT (the stratigraphy is illustrated in Figure 5a and only the LBPT was excavated). The purpose of this is to investigate whether the two tunnels interacted during the seismic event by comparing the 1BPT-AB dynamic analysis results with those previously obtained by the dynamic analysis 2BPTs-AB.

The second set of analyses, denoted in future discussions as 1BPT-CD, concerns dynamic analyses of the stratigraphy of cross-section CD (see Figure $5 b$ ). The purpose of this set of analyses is to examine whether the different stratigraphy resulted in lower seismic loads in the LBPT at chainage $62+870$ compared with those predicted by the analysis 1BPT-AB. The finite element mesh used in the second set of analyses, consists of 5274 8-noded quadrilateral solid elements and 31 3-noded beam elements. The depth of the mesh for the cross section CD is $183.0 \mathrm{~m}$, while the width was taken the same as before (i.e. $219.0 \mathrm{~m}$ ). 
It should be noted that when the earthquake struck, the shotcrete at chainage $62+870$ was 8 days old. In this set of analyses (i.e.1BPT-CD) the LBPT was constructed at $60 \%$ stress relaxation and at the end of the excavation process was assigned the material properties that correspond to the RBPT in Table 5 (as the RBPT's shotcrete at chainage $62+850$ had similar age when the earthquake struck). All other analysis arrangements (i.e. boundary conditions, time integration e.t.c.) were kept the same as those used in the analyses of the cross section AB.

Figure 17 compares the maximum shear strain profiles (caused only by the dynamic excitation) predicted by the three analyses (i.e. 2BPTs-AB, 1BPT-AB and 1BPT-CD) at $x=70.0 \mathrm{~m}$ and at $\mathrm{x}=0.0 \mathrm{~m}$. The free-field response (i.e. at $\mathrm{x}=70.0 \mathrm{~m}$ ) obtained by the 2BPT-AB and 1BPT-AB analyses is very similar. This is not surprising, since if the width of the mesh and the lateral boundaries have been appropriately chosen, the free field response should not be affected by the structure. On the other hand, the 1BPT-CD analysis predicts lower free-field response for the fault gouge clay (i.e. layer 4) than the other two analyses. Hence, although the thickness of the fault gouge clay layer is the same in all analyses, the response of the gouge clay seems to be affected by the thickness of the overlaying layer (i.e. metasediments). Conversely, the response of the other materials does not seem to be significantly affected by the stratigraphy. Furthermore, in all analyses, the maximum shear strain profile in the pillar at the level of the tunnel (i.e. the centre of the tunnel is at $\mathrm{z}=160.0 \mathrm{~m}$ and the centre of the pillar is at $\mathrm{x}=0 \mathrm{~m}$ ) is amplified with respect to the corresponding free-field profile. However, the 1BPT-AB analysis predicts lower amplification than the 2BPTs-AB analysis. This difference is quite small, but it indicates that some interaction between the tunnels takes place in the 2BPTs-AB analysis. Besides, the amplification is even lower in the 1BPT-CD analysis, suggesting that the stratigraphy rather than the interaction of the tunnels is the crucial parameter.

Figure 18 illustrates the first 20 seconds of the shear strain time histories recorded at the integration points $\mathrm{R}(\mathrm{x}=69.26 \mathrm{~m}, \mathrm{z}=160.7 \mathrm{~m}$, i.e. free-field location) and $\mathrm{S}(\mathrm{x}=0.235 \mathrm{~m}, \mathrm{z}=160.7 \mathrm{~m}$, i.e. pillar location) for the three analyses. Figure 18a shows that the 1BPT-CD analysis gives consistently the lowest response, while the 1BPT$\mathrm{AB}$ and $2 \mathrm{BPTs}-\mathrm{AB}$ analyses predict almost identical response. In the pillar, the 
maximum shear strain predicted by the $2 \mathrm{BPTs}-\mathrm{AB}$ analysis is $17 \%$ higher than the one predicted by the 1BPT-AB analysis and 33\% higher than the one predicted by the 1BPT-CD analysis. It should be noted that all analyses gave approximately the same value of permanent shear strain at the end of the analysis.

Table 8 summarizes the predicted maximum hoop stress at the LBPT from the three analyses. It is interesting to note that the 2BPTs-AB and 1BPT-AB analyses predict the same total maximum hoop stress while that obtained by the 1BPT-CD analysis is only $10 \%$ lower. Overall the 1BPT-CD analysis results show that the LBPT was subjected to lower loads at chainage $62+870$. However, the predicted maximum hoop stress exceeds the 8-days shotcrete strength which is estimated to be 30.0 MPa. As discussed earlier, since the lining is modelled as a linear elastic material, it is expected that all three analyses overestimate to some extent the loads that were actually acting on it.

In conclusion, it was shown that the interaction of the BPTs and any potential wave reflections in the pillar had only a minor effect on the seismic tunnel performance. On the other hand, comparison of the 1BPTs-AB and 1BPT-CD analyses showed that the differences in stratigraphy considerably affect the tunnel response. However, these differences cannot fully explain the lack of serious damage in the cross section $\mathrm{CD}$. To further investigate this, a full 3D model and a more realistic modelling of the tunnel linings would be needed.

\subsection{Comparison with simplified methods of analysis}

Due to the complexity and the high computational cost of dynamic FE analyses, it is often preferred to employ simplified analytical solutions and/or quasistatic FE methods to investigate the seismic response of tunnels. Although such simplified methods cannot properly model the changes in soil stiffness and strength that take place during an earthquake and they ignore any dynamic SSI effects, they often give a reasonable estimate of the seismic loads. Commonly, dynamic SSI effects are important for cases in which the dimensions of the cross-section are comparable with the dominant wavelengths of the ground motion, for shallow burial depths and in cases of stiff structures in soft soil. The dimensions and the burial depth in the 
examined case study are such that the dynamic SSI effects are not expected to have played a significant role in the collapse of the tunnels. Therefore, it is interesting to examine how the results of these simplified methodologies compare with those obtained by dynamic analysis presented for chainage $62+850$ and with postearthquake field observations.

\subsubsection{Comparison with analytical solutions}

The extended Hoeg (Hoeg 1968 and Schwartz and Einstein 1980) ${ }^{3}$ and the Penzien (2000) solutions, assuming either full-slip or non-slip conditions along the interface between the ground and the lining, express the maximum thrust $\left(\mathrm{T}_{\max }\right)$ and the maximum bending moment $\left(\mathrm{M}_{\max }\right)$ of the tunnel lining as a function of the maximum free-field shear strain $\left(\gamma_{\max }\right)$ at the level of the tunnel and properties of the soil and the lining. The assumed parameters are listed in Table 9, while the $\gamma_{\max }$ at the level of the tunnels was taken from the 1D analysis with the M2-SKH model equal to $0.19 \%$ (see Figure 10). Furthermore, Tables 10 and 11 summarize the analytical results for the LBPT and RBPT respectively.

The Penzien approach seems not to be so sensitive to the assumed condition along the interface between the ground and the lining and in all cases predicts much lower hoop stress values than those predicted by the extended Hoeg method. The field observations indicated that the maximum hoop stress acting on the tunnels lining due to static loading was on average $10 \mathrm{MPa}$, the total hoop stress based on the Penzien method is then $24.15 \mathrm{MPa}$ and $20.7 \mathrm{MPa}$ for the LBPT and the RBPT respectively. These values are much lower than the estimated strength of shotcrete at the time of the earthquake (40MPa and $30 \mathrm{MPa}$ for the LBPT and RBPT respectively). Consequently, as failure was observed in the field, it can be concluded that the Penzien (2000) methodology underestimates the maximum hoop stress developed due to the earthquake in the BPTs. It should be noted that Hashash et al (2005) performed quasi-static elastic FE analyses to validate the extended Hoeg and Penzien methods

\footnotetext{
${ }^{3}$ The extended Hoeg solution was later summarised by Wang (1993) and it is often referred as the Wang (1993) solution.
} 
for non-slip conditions and they also concluded that the latter one significantly underestimates the thrust in the tunnel lining for the condition of non-slip.

On the other hand, the extended Hoeg method gives much higher values of maximum thrust for the no-slip assumption than for the full-slip assumption. The fullslip condition is a reasonable approximation in cases of tunnels in soft soils, while for tunnels in stiff soils (i.e. like the BPTs) it leads to underestimation of the maximum thrust. It should be noted that the FE analyses presented herein are more consistent with the no-slip assumption. This is because, as previously discussed, the mobilised strength ratio of the soil at the tunnel-soil boundary was well below 1 throughout the dynamic analysis (see Figure 13). For both BPTs the predicted seismic hoop stresses by the extended Hoeg method under the no-slip assumption compare reasonably well to those predicted by the FE analysis in Table 7 (i.e. compare earthquake values).

Furthermore, since the static hoop stress was on average $10 \mathrm{MPa}$, the total hoop stress acting on the lining based on the extended Hoeg method for the no-slip assumption is then $36.8 \mathrm{MPa}$ and $32.8 \mathrm{MPa}$ for the LBPT and the RBPT respectively. In conclusion, the extended Hoeg method, for the no-slip assumption, predicts hoop stresses that match quite well with the post-earthquake field observations. On the other hand the use of the Penzien solution for non-slip conditions should be avoided as it severely underestimates the seismically induced maximum thrust

\subsubsection{Quasi-static FE analyses}

Usually, a quasi-static analysis approximates the earthquake induced inertia forces as a constant horizontal body force applied throughout the mesh. In the present study however, a different approach was followed. Initially a conventional static analysis, as previously described, was undertaken to establish the static loads acting on the tunnels. Once the construction sequence was modelled, the mesh was subjected to simple shear conditions, as shown schematically in Figure 19. During the quasistatic analysis the vertical displacements were restricted along all mesh boundaries, while the horizontal displacements were restricted along the bottom boundary. Furthermore, a uniform displacement $\mathrm{u}_{\mathrm{s}}$ and a triangular displacement distribution, as illustrated in Figure 19, were applied over 200 increments along the top and the lateral boundaries of the mesh respectively. The displacement $\mathrm{u}_{\mathrm{s}}$ was calculated as follows: 


$$
\mathrm{u}_{\mathrm{s}}=\gamma_{\max } \mathrm{H}=0.0019 \times 195.0 \mathrm{~m}=0.3705 \mathrm{~m}
$$

where $\mathrm{H}$ is the depth of the mesh and $\gamma_{\max }$ is the maximum free-field shear strain at the level of the tunnels calculated by the 1D dynamic analysis (see Figure 10).

Figure 20 illustrates the maximum (i.e. calculated at the last increment) accumulated thrust, bending moment and hoop stress distribution around the tunnel linings computed with the M2-SKH model. In a similar fashion to the results of the corresponding dynamic analysis (see Figure 15) the load distribution is highly nonuniform around the tunnel linings and the maxima of the thrust, bending moment and hoop stress variations occur at shoulder and knee locations. Comparison of Figures 15 and 20 shows that the quasi-static analysis predicts lower values of thrust than the dynamic analysis. Conversely, the quasi-static analysis predicts much higher bending moments. The predicted hoop stress variation by the two analyses, which combines the effect of the axial force and the bending moment, is fairly similar especially at shoulder and knee locations.

While it is difficult to draw general conclusions from this set of analyses, it seems that the quasi-static analysis' results in terms of hoop stresses compare reasonably well with those obtained by the corresponding dynamic analysis.

\subsection{Conclusions}

This paper presents a case study of the Bolu highway twin tunnels that experienced a wide range of damage during the 1999 Duzce earthquake in Turkey. Attention was focused on a particular section of the left tunnel that was still under construction when the earthquake struck and that experienced extensive damage during the seismic event. At the time of the earthquake only the two shotcrete supported bench pilot tunnels (BPTs) had been constructed. The post-earthquake investigations showed that the damage was limited to a zone of fault gouge clay where the two tunnels overlapped. In the same material, the leading portion of the left BPT (LBPT), where the adjacent RBPT had not been constructed, did not suffer extensive damage. 
Static and dynamic plane strain FE analyses were undertaken to investigate the seismic tunnel response at two sections and to compare the results with the postearthquake field observations. The analyses of the first section (section $\mathrm{AB}$ ) refer to the area that the two BPTs overlap, while the analyses of the second section (section CD) refer to the area where the leading portion of the LBPT did not experience severe damage (Figure 4). The main purpose of the second set of analyses (i.e. section CD) was to investigate why the leading portion of the LBPT tunnel did not experience severe damage.

In the last part of the study the results of the dynamic analyses of section $A B$ were compared with those obtained by the simplified analytical elastic solutions using the extended Hoeg (Hoeg 1968 and Schwartz and Einstein 1980) and Penzien (2000) methods and those obtained by quasi-static FE elasto-plastic analyses in which freefield racking deformation was imposed.

Several conclusions can be drawn from the results of the present study:

1. The tunnels deformed predominantly in an oval shape, with the maxima of the thrust, bending moment and hoop stress occurring at shoulder and knee locations of the lining. This is in agreement with post-earthquake field observations at the severely damaged section of the LBPT (see Figure 3).

2. The numerical model depicted the observed failure at section $A B$, as the maximum total hoop stress values exceed the strength of the shotcrete in both tunnels. However, since the cracking of the lining was not modelled in the present study, the predicted loads might deviate to some extent from the loads that were actually acting on it.

3. It was shown that the interaction of the two BPTs and any wave reflections in the pillar in between them only had a minor effect on their seismic performance.

4. The observed differences in the seismic performance of the LBPT in sections $\mathrm{AB}$ and $\mathrm{CD}$ can be partly attributed to the differences in stratigraphy between the two locations. 
5. The $2 \mathrm{D}$ FE analyses cannot fully explain the lack of serious damage in the cross section $\mathrm{CD}$, as the predicted maximum hoop stress exceeded the shotcrete strength. To further investigate this, a full 3D model and a more realistic modelling of the tunnel linings would be needed.

6. The extended Hoeg method, assuming no-slip between soil and lining, predicts hoop stresses that match quite well with the dynamic FE analyses and the post-earthquake field observations.

7. The Penzien (2000) method underestimated the maximum hoop stress developed due to the earthquake in the BPTs. The use of the Penzien solution for non-slip conditions should be avoided as it severely underestimates the seismically induced maximum thrust. This is in agreement with the findings of Hashash et al (2005).

8. The comparison of the quasi-static analysis results with those obtained from the dynamic analyses showed significant differences in the thrust and bending moment distributions around the lining, but the resulting hoop stress distributions were in reasonable agreement. 


\subsection{Acknowledgements}

The many contributors to the construction of Bolu Tunnels are acknowledged. The Contractor was Astaldi-Bayindir JV, advised by Geoconsult and Lombardi S.A. The Engineer was Yuksel-Rendel JV with input from GCG. The Employer was KGM. The authors are also indebted to Profs Mair and O' Rourke who were colleagues on the project.

\subsection{References}

Akkar, S., and Gülkan, P. 2002. A critical examination of near-field accelerograms from the sea Marmara region earthquakes. Bulletin of the Seismological Society of America, 92(1): 428-447.

Archuleta, R.J., Steidl, J.H., and Bonilla L.F. 2000. Engineering insights from data recorded on vertical arrays. In Proceedings of the 12th World Conference in Earthquake Engineering, 30 January- 4 February 2000, New Zealand, Paper 2681

Bardet J.P., Ichii K., and Lin C.H. 2000). EERA, A computer program for Equivalent linear Earthquake site Response Analysis of layered soils deposits. Report of the University of Southern California, Los Angeles.

Barka A., and Altunel E. 2000. Preliminary report on whether the Asarsu valley is active fault controlled. Report prepared for Astaldi-Bayindir Joint Venture.

Bielak J., Loukakis K., Hisada Y., and Yoshimura C. 2003. Domain Reduction Method for Three-Dimensional Earthquake Modelling in Localized Regions, Part I: Theory. Bulletin of the Seismological Society of America, 93(2):817824.

Chung J., and Hulbert, G.M. 1993. A time integration algorithm for structural dynamics with improved numerical dissipation: the generalized- $\alpha$ method. Journal of Applied Mechanics, 60: 371-375. 
Federal Highway Administration (FHWA), 2000. Seismic retrofitting manual for highway structures, part II. Report prepared by the Multidisciplinary Centre for Earthquake and Engineering Research, Buffalo, New York.

Grammatikopoulou A. 2004. Development, implementation and application of kinematic hardening models for overconsolidated clays. $\mathrm{PhD}$ thesis, Department of Civil and Environmental Engineering, Imperial College, London.

Grammatikopoulou A., Zdravkovic L., and Potts, D.M. 2006. General formulation of two kinematic hardening constitutive models with a smooth elastoplastic transition. International Journal of Geomechanics, 6 (5): 291-302.

Hashash Y.M.A., Hook J.J., Schmidt B., and Yao J.I-C., 2001. Seismic design and analysis of underground structures. Tunnelling and Underground Space Technology, 16(4): 247-293.

Hashash Y.M.A., Park D. and Yao J.I-C., 2005. Ovaling deformations of circular tunnels under seismic loading, an update on seismic design and analysis of underground structures. Tunnelling and Underground Space Technology, 20(5): 435-441.

Hoeg, K. 1968. Stresses against underground structural cylinders. Journal of Soil Mechanics and Foundation Division, ASCE, 94(4): 833-858.

Kontoe S. 2006. Development of time integration schemes and advanced boundary conditions for dynamic geotechnical analysis. PhD thesis, Department of Civil and Environmental Engineering, Imperial College, London.

Kontoe S., Zdravković L., and Potts D.M. 2008a. An assessment of time integration schemes for dynamic geotechnical problems. Computers and Geotechnics, 35(2): 253-264.doi:10.1016/j.compgeo.2007.05.001

Kontoe S., Zdravković L., and Potts D.M. 2008b. An assessment of the Domain Reduction Method as an advanced boundary condition and some pitfalls in the use of conventional absorbing boundaries. Accepted for publication in the 
International Journal for Numerical and Analytical Methods in Geomechanics, in press. doi:10.1002/nag.713

Kuhlemeyer R.L., and Lysmer J. 1973. Finite element method accuracy for wave propagation problems. Technical Note, Journal of Soil Mechanics and Foundation Division, ASCE, 99(5):421-427.

Lettis, W., and Barka A. 2000. Geologic characterisation of fault rupture hazard, Gumusova-Gerede Motorway. Report prepared for the Astaldi-Bayindir Joint Venture.

Lysmer J. and Kuhlemeyer R.L. 1969. Finite dynamic model for infinite media. Journal of the Engineering Mechanics Division, ASCE, 95 (4): 859-877.

Menkiti C.O., Mair R.J., and Miles R. 2001b. Tunneling in complex ground conditions in Bolu, Turkey. In the Proceedings of the Underground Construction 2001 Symposium, London. pp.546-558.

Menkiti C.O., Sanders P., Barr J., Mair R.J., Cilingir, M. and James S. 2001a. Effects of the $12^{\text {th }}$ November 1999 Duzce earthquake on the stretch 2 the GumusovaGerede Motorway in Turkey. In the Proceedings of the International Road Federation $14^{\text {th }}$ World Road Congress, Paris.

O’Rourke T.D., Goh S.H., Menkiti, C.O., and Mair R.J., 2001. Highway tunnel performance during the 1999 Duzce earthquake. In the Proceedings of the Fifteenth International Conference on Soil Mechanics and Geotechnical Engineering, 27-31 August 2001, Istanbul, Turkey. Vol.2, pp. 1365-1368. Balkema.

Owen G.N., and Scholl R.E., 1981. Earthquake engineering of large underground structures. Report no. FHWA/RD-80/195, Federal Highway Administration and National Science Foundation.

Penzien, J. 2000. Seismically induced racking of tunnel linings. International Journal of Earthquake Engineering and Structural Dynamics, 29(5): 683-691. 
Potts D.M., and Zdravković L.T. 1999. Finite element analysis in geotechnical engineering: theory. Thomas Telford, London.

Potts D.M., and Zdravković L.T. 2001. Finite element analysis in geotechnical engineering: application. Thomas Telford, London.

Schwartz, C.W., and Einstein, H.H. 1980. Improved Design of Tunnel Supports: Vol.1- Simplified Analysis for Ground-structure Interaction in Tunneling. UMTA-MA-06-0100-80-4, Urban Mass Transit Transportation Administration, MA.

Seed H. B., Wong R. T., Idriss I. M., and Tokimatsu K. 1986. Moduli and damping factors for dynamic analyses of cohesionless soils. Journal of the Geotechnical Engineering Division, ASCE, 112(1): 1016-1032.

St. John C.M., and Zahrah T.F. 1987. Aseismic design of underground structures. Tunnelling and Underground Space Technology, 2(2):165-197.

Sucuoğlu H., 2002. Engineering characteristics of the near-field strong motions from the 1999 Kocaeli and Düzce Earthquakes in Turkey. Journal of Seismology. 6(1): pp. 347-355.

Vucetic M., and Dobry R., 1991. Effect of soil plasticity on cyclic response. Journal of Geotechnical Engineering, ASCE, 117(1): 89-107.

Wang J.N. 1993. Seismic Design of Tunnels: A State-of-the-Art Approach. Monograph 7, Parsons, Brinckerhoff, Quade and Douglas Inc, New York. 


\subsection{List of Figures}

Figure 1: The surface rupture of the November 1999 Düzce earthquake and active faults around Bolu

Figure 2: Design solution for the thick zones of fault gouge clay (after Menkiti et al 2001b)

Figure 3a: View of the damaged $5 \mathrm{~m}$ diameter LBPT, stabilised by backfilling with foam concrete. Picture taken during re-excavation and construction of a replacement lining.

Figure 3b: Typical detail at location $\mathrm{X}$ between $\mathrm{Ch} 62+835$ and $62+865$ showing damage to steel ribs within the shotcrete lining

Figure 4: Plan view of the Asarsuyu left drive showing the main tunnel and two bench pilot tunnels under construction at the time of the earthquake

Figure 5: Ground profiles at chainage $62+850$ (cross-section AB) (a) and at chainage $62+870$ (cross-section CD) (b).

Figure 6: FE mesh configuration for chainage $62+850$ after the excavation of the tunnels

Figure 7: Scaled and truncated accelerogram used in the FE analyses (a) and corresponding Fourier spectrum (b)

Figure 8: Accumulated thrust (a), bending moment (b) and maximum hoop stress (c) distributions around the tunnels' lining at the end of the static analysis

Figure 9: Contours of pore pressure distribution around the tunnels at the end of the static analysis.

Figure 10: Maximum shear strain profile computed with the M2-SKH model for 1D and $2 \mathrm{D}$ analyses

Figure 11: Enlarged view of the deformed mesh at $\mathrm{t}=8.0 \mathrm{sec}$ 
Figure 12: Contours of deviatoric stress ( $\mathrm{J}$ ) (at $\mathrm{t}=5.0,6.0,7.0$ and 8.0sec) in the vicinity of the tunnels (for the area indicated in Figure 11)

Figure 13: Mobilised strength ratio along BPTs' lining at $\mathrm{t}=5 \mathrm{sec}$ (a) and at $\mathrm{t}=10 \mathrm{sec}$

Figure 14: Pore water pressure (a) and shear strain (b) time histories for integration points adjacent to the crowns of the BPTs

Figure 15: Accumulated thrust (a), bending moment (b) and maximum hoop stress (c) distribution around the tunnels' lining at $\mathrm{t}=10.0 \mathrm{sec}$

Figure 16: Thrust (a) and bending moment (b) time histories at $\theta=137^{\circ}$ for both BPTs

Figure 17: Maximum shear strain profile computed with the 2BPTs-AB, the 1BPT$\mathrm{AB}$ and the 1BPT-CD model at $\mathrm{x}=70.0 \mathrm{~m}(\mathrm{a})$ and $\mathrm{at}=0.0 \mathrm{~m}(\mathrm{~b})$

Figure 18: Shear strain time histories computed with the 2BPTs-AB, the 1BPT-AB and the 1BPT-CD model at integration points $\mathrm{R}$ and $\mathrm{S}$

Figure 19: Schematic representation of FE mesh configuration in quasi-static analysis

Figure 20: Accumulated thrust (a), bending moment (b) and maximum hoop stress (c) distribution around the tunnels' lining at the end of the quasi-static analysis

\subsection{List of symbols}

Bulk unit weight of soil.

Maximum free-field shear strain.

Area per unit width of the lining cross-section.

c'

Cohesion intercept of a soil.

E

Young's modulus.

$f_{\max }$

Maximum frequency of the input wave 
Shear modulus.

$\mathrm{g}(\theta) \quad$ Gradient of the yield function in the $\mathrm{J}-\mathrm{p}^{\prime}$ plane, as a function of Lode's angle.

$\mathrm{g}_{\mathrm{pp}}(\theta) \quad$ Gradient of the plastic potential function in the $\mathrm{J}-\mathrm{p}^{\prime}$ plane, as a function of Lode's angle.

Moment of inertia.

$\mathbf{J}$

Deviatoric stress.

$\mathrm{K}_{0}$

Coefficient of earth pressure at rest.

M

Bending moment in tunnel lining.

$\mathrm{M}_{\max }$

Maximum bending moment in tunnel lining.

$\mathrm{p}^{\prime}$

Mean effective stress.

$\mathrm{R}$

Tunnel lining-soil racking ratio.

$\rho$

Material density.

$\mathrm{V}_{\mathrm{S} \min }$

Minimum shear wave velocity

$\mathrm{S}_{\mathrm{u}}$

Undrained strength

$\sigma_{H}$

Hoop stress

$\mathrm{t}$

Thickness of tunnel lining.

Thrust force in tunnel lining.

$\mathrm{T}_{\max }$

Maximum thrust in tunnel lining. 
Length of an element side.

$\Delta \mathrm{t}$

Incremental time step.

$\theta$

Lode's angle.

$v$

Poisson's ratio.

$\varphi^{\prime}$

Angle of internal shearing resistance of a soil. 


\subsection{Figures}




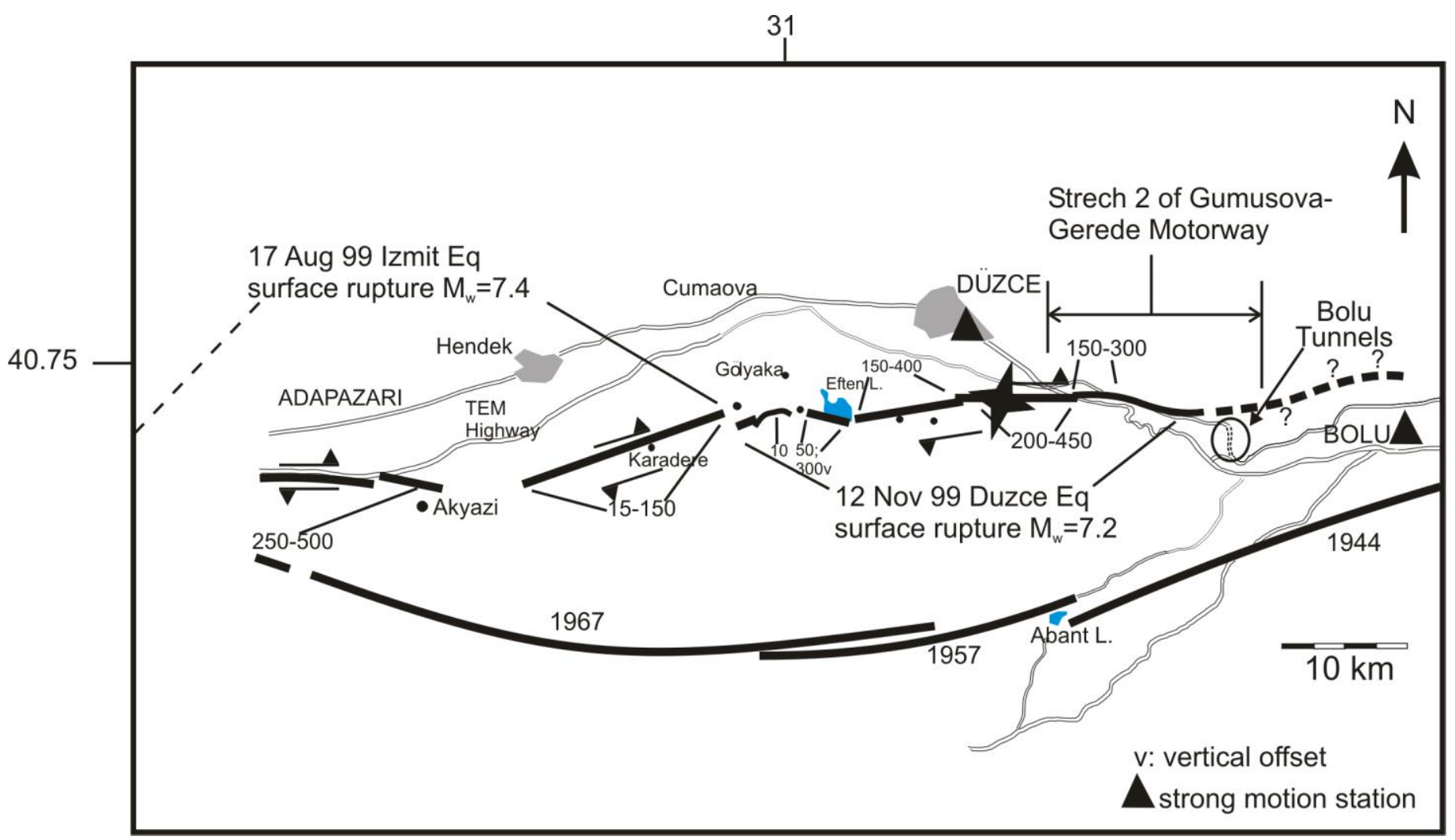

Figure 1: The surface rupture of the November 1999 Düzce earthquake and active faults around Bolu 


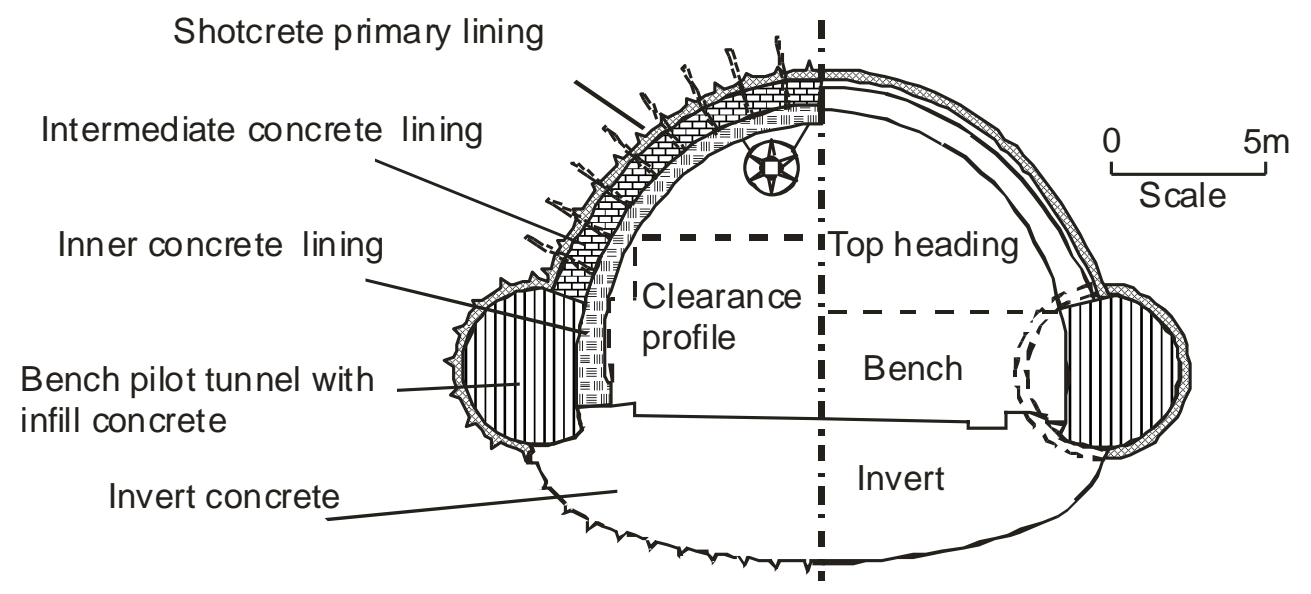

Figure 2: Design solution for the thick zones of fault gouge clay (after Menkiti et al 2001b) 


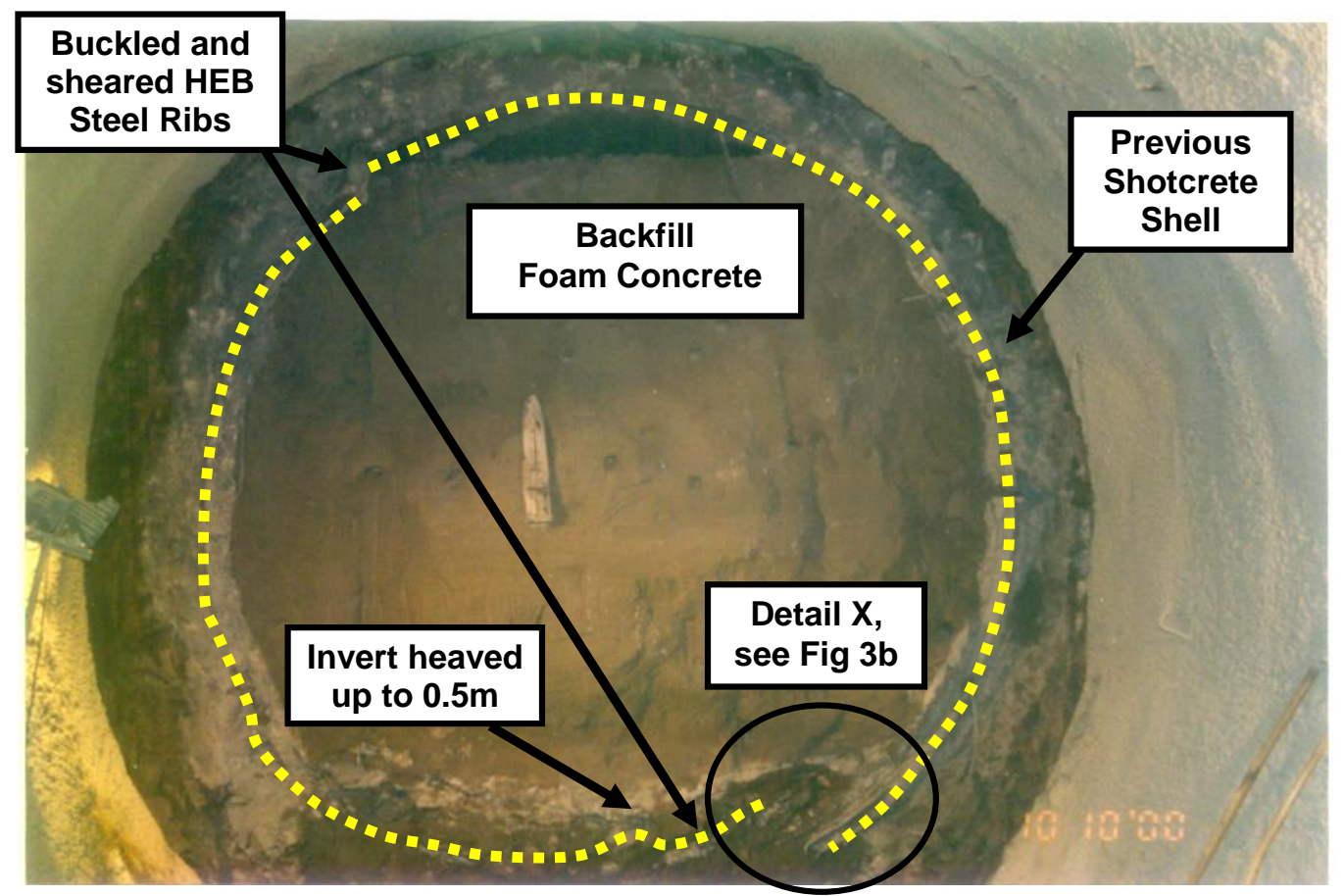

Figure 3a: View of the damaged 5m diameter LBPT, stabilised by backfilling with foam concrete. Picture taken during re-excavation and construction of a replacement lining.

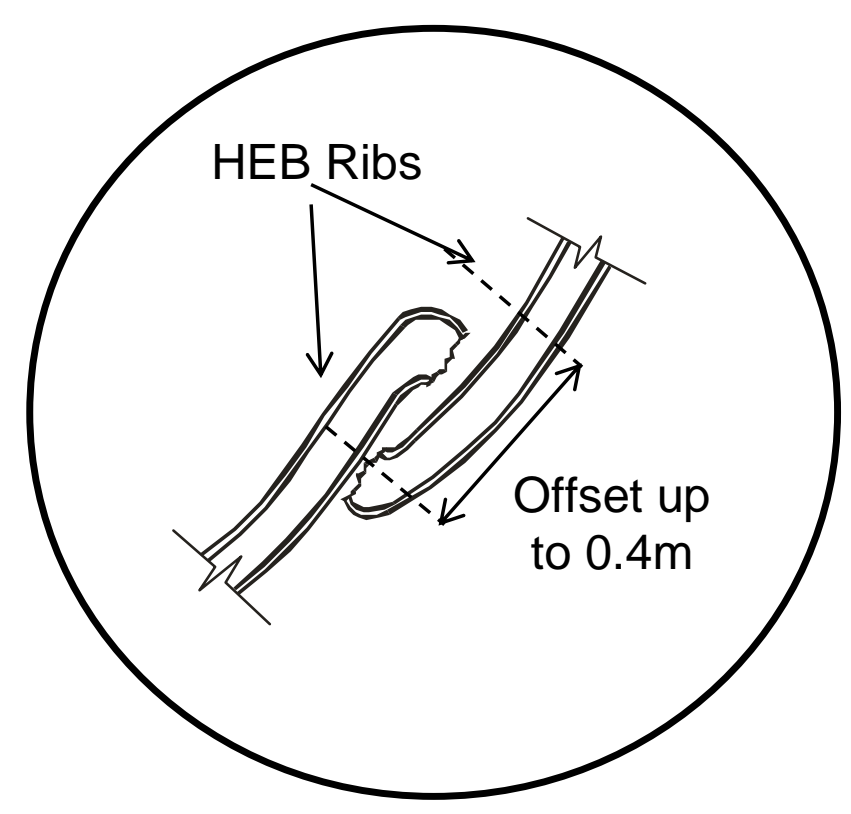

Figure 3b: Typical detail at location $\mathrm{X}$ between $\mathrm{Ch} 62+835$ and $62+865$ showing damage to steel ribs within the shotcrete lining 


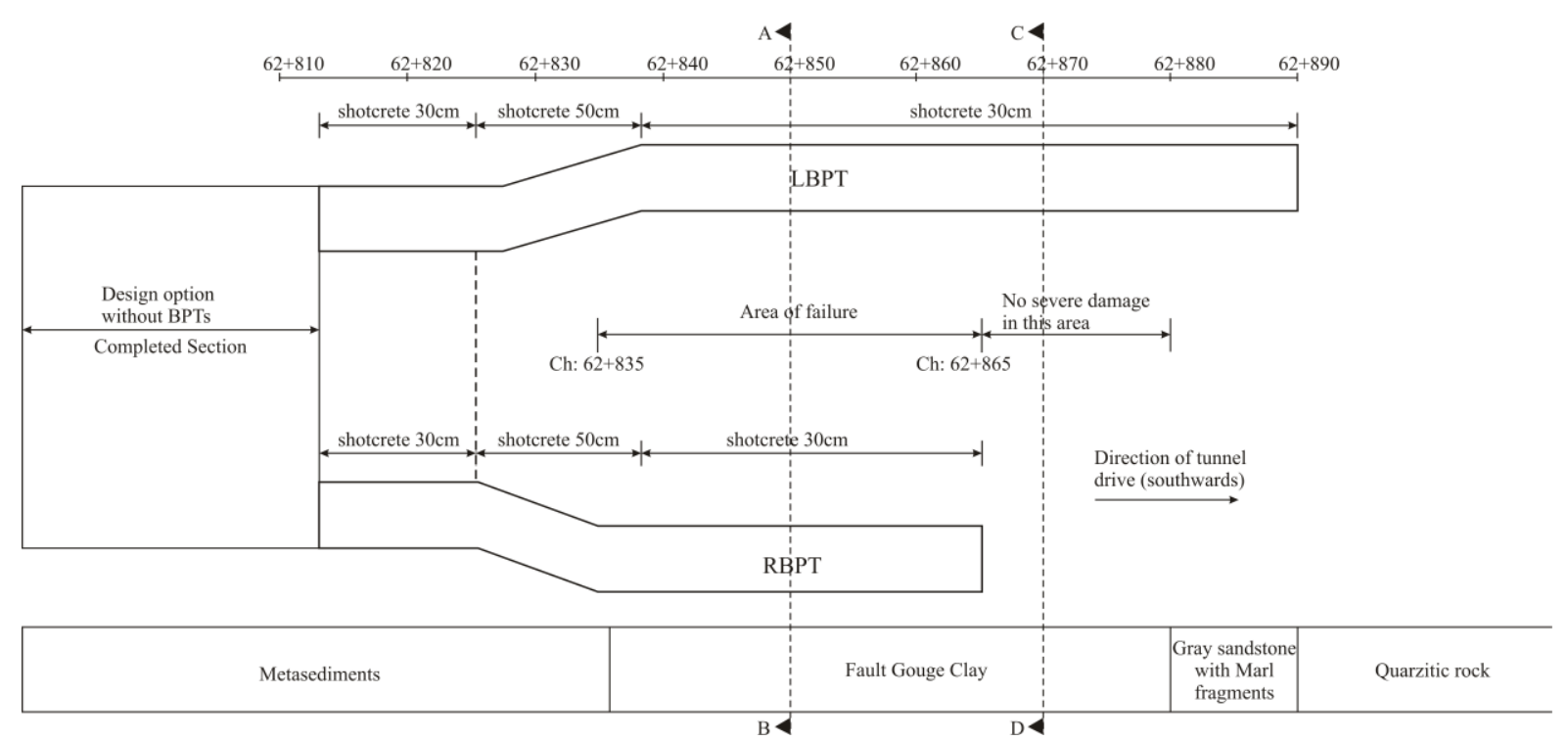

Figure 4: Plan view of the Asarsuyu left drive showing the main tunnel and two bench pilot tunnels under construction at the time of the earthquake 


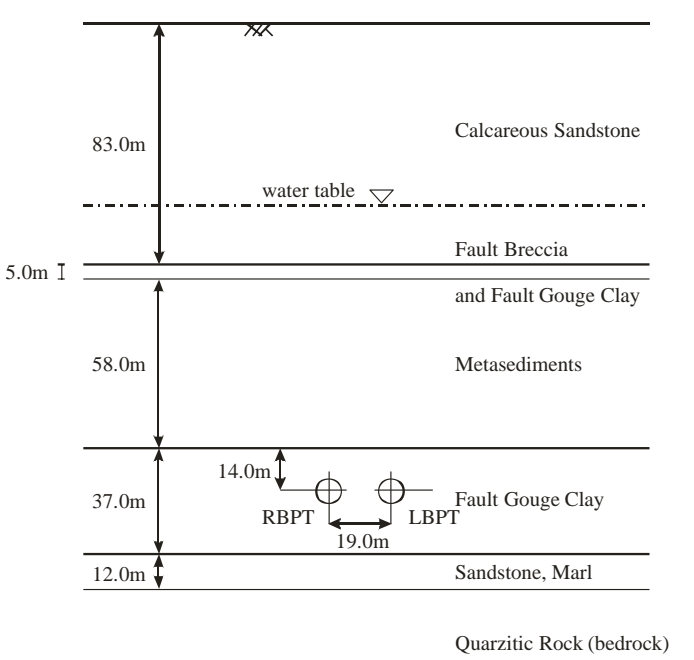

(a)

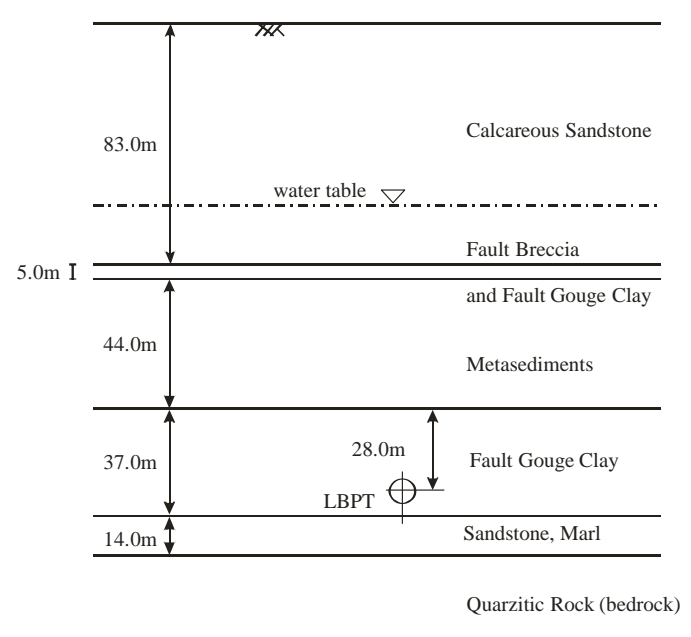

(b)

Figure 5: Ground profiles at chainage 62+850 (cross-section AB) (a) and at chainage $62+870$ (cross-section CD) (b).

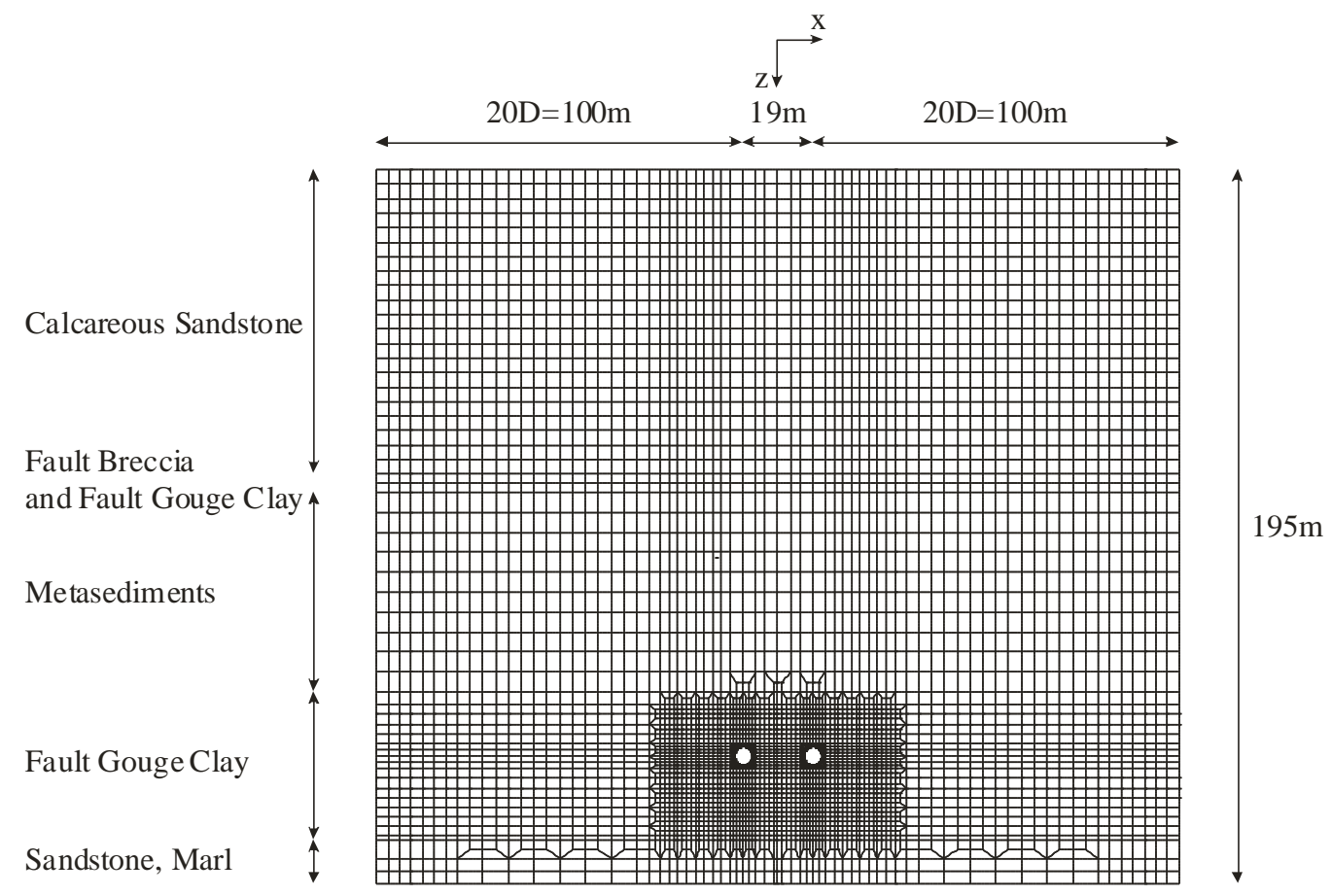

Figure 6: FE mesh configuration for chainage $62+850$ after the excavation of the tunnels 

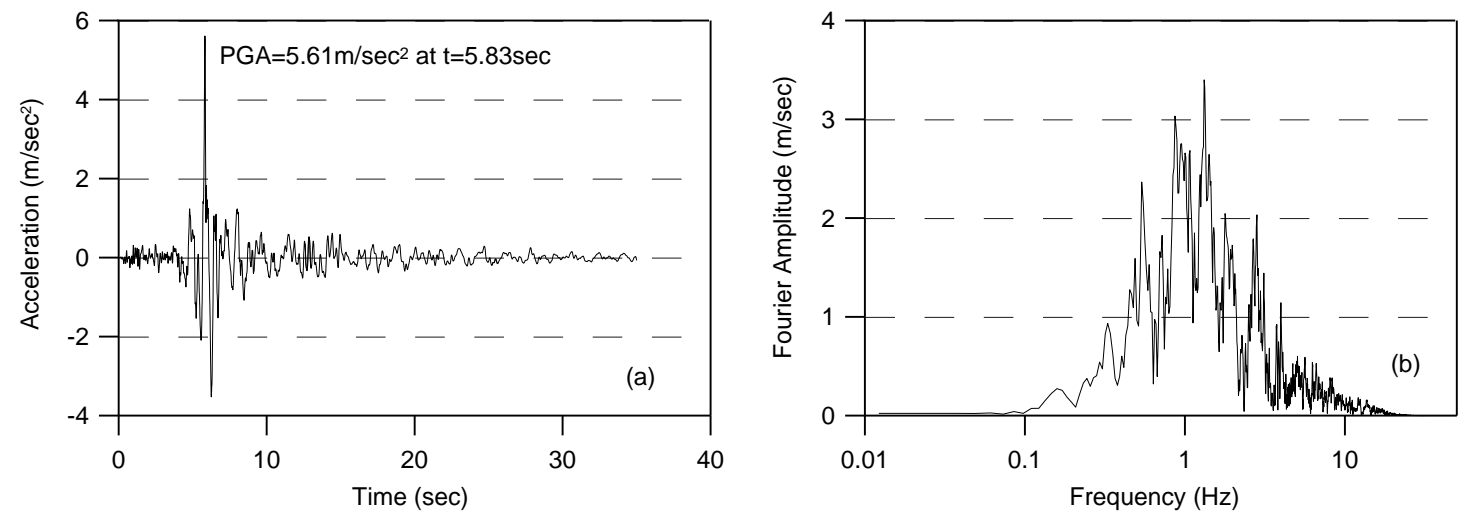

Figure 7: Scaled and truncated accelerogram used in the FE analyses (a) and corresponding Fourier spectrum (b)
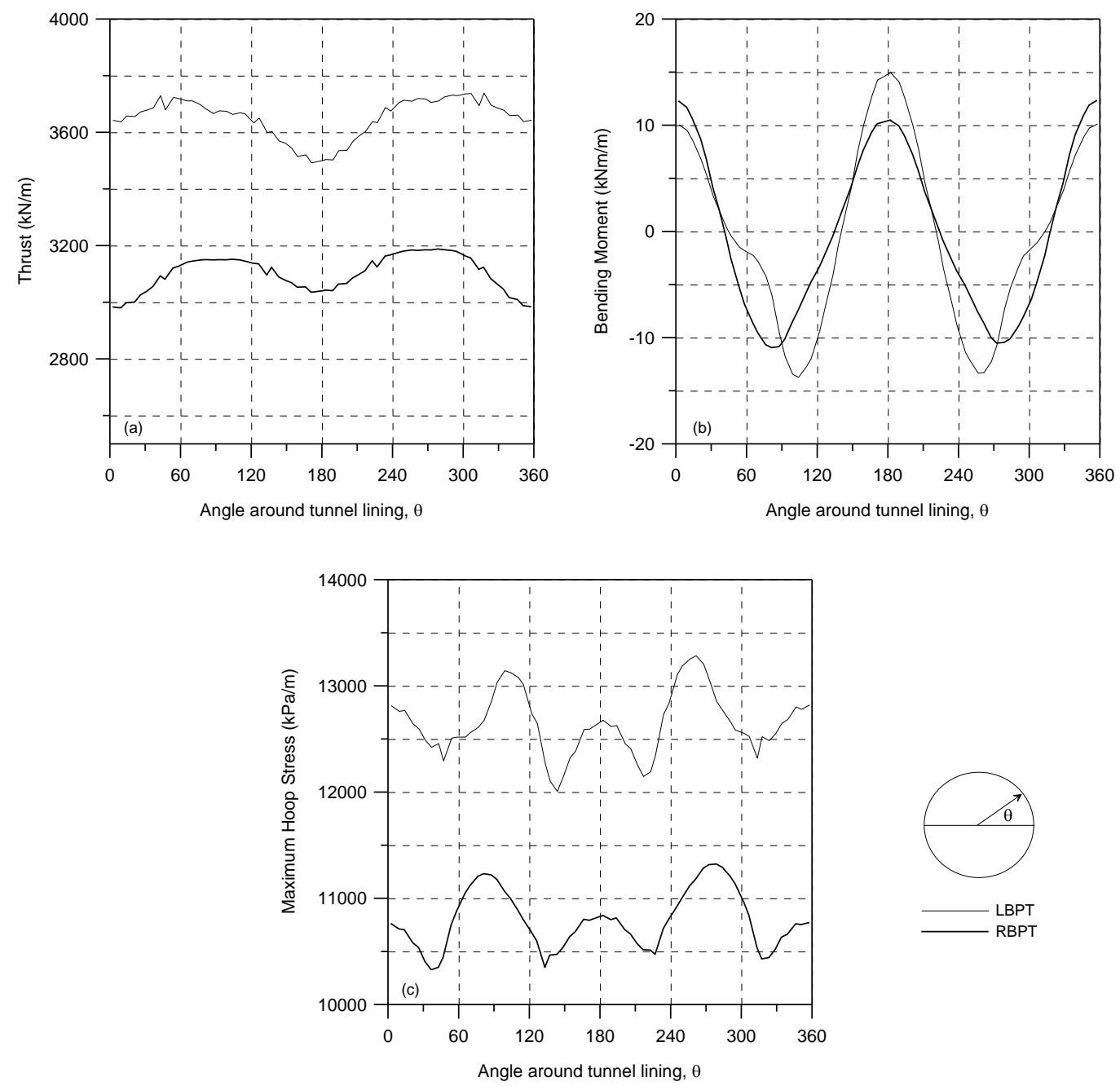

Figure 8: Accumulated thrust (a), bending moment (b) and maximum hoop stress (c) distributions around the tunnels' lining at the end of the static analysis 


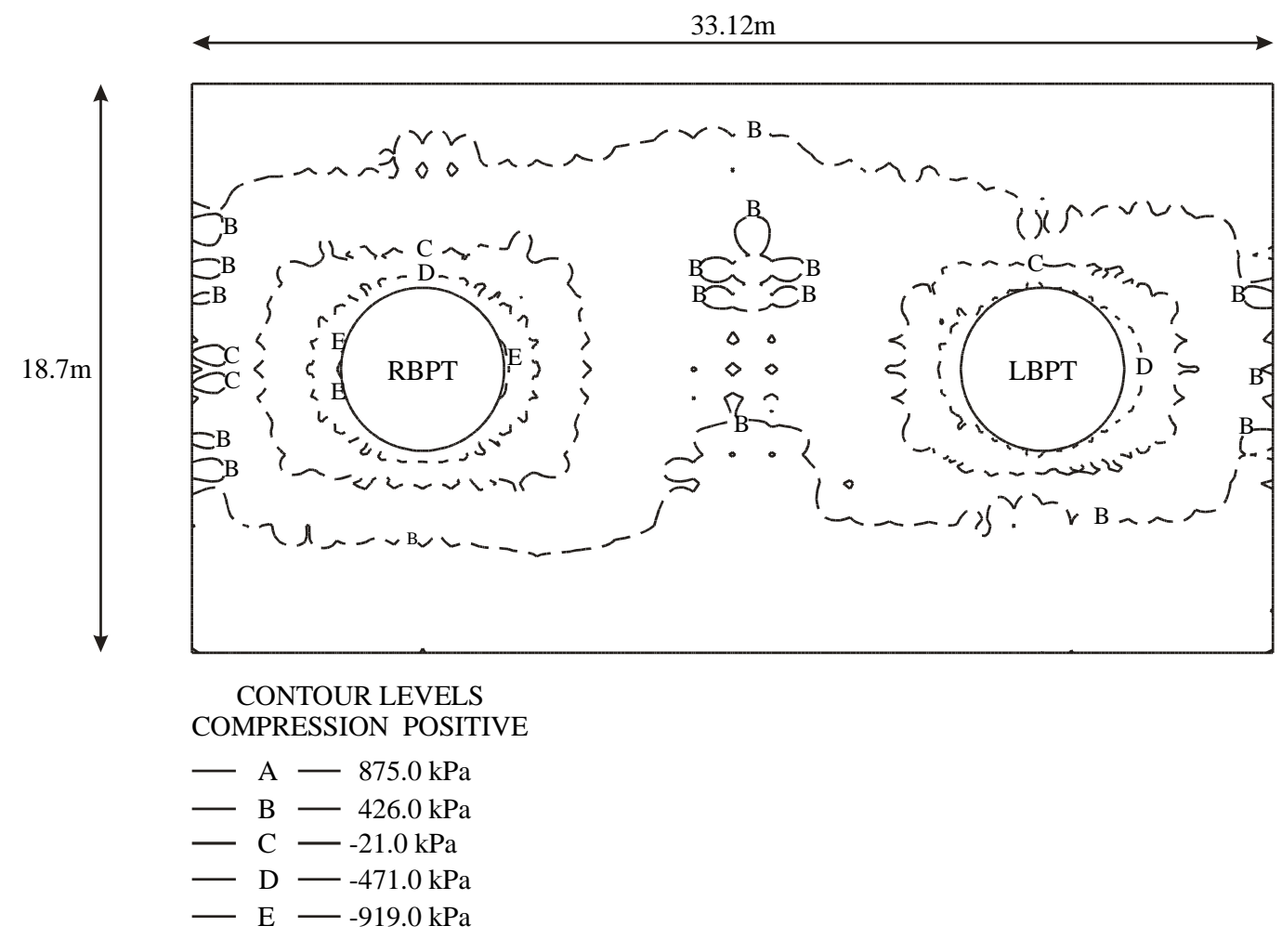

Figure 9: Contours of pore pressure distribution around the tunnels at the end of the static analysis.

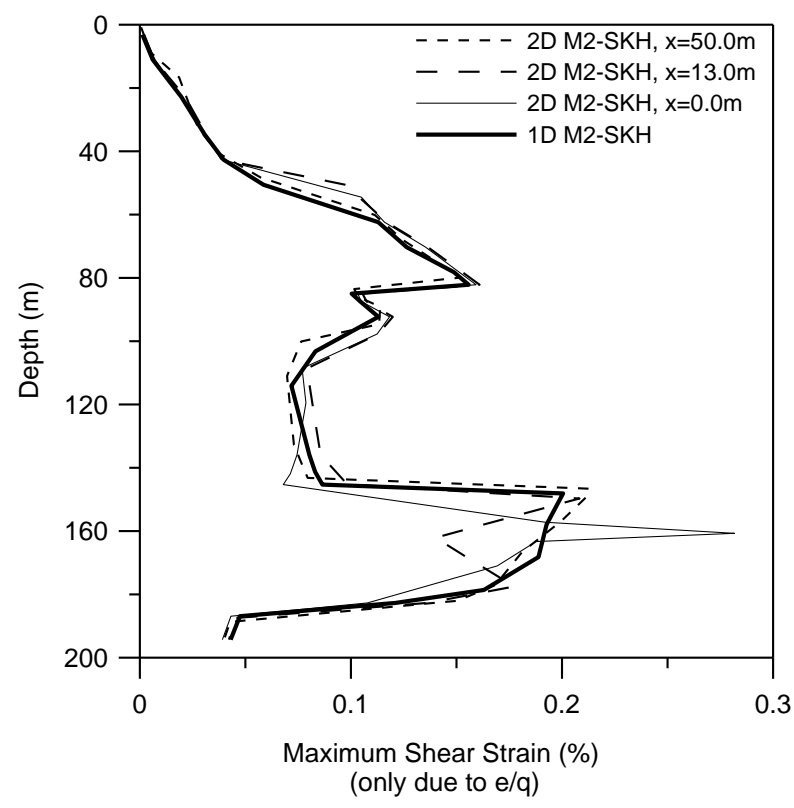

Figure 10: Maximum shear strain profile computed with the M2-SKH model for 1D and $2 \mathrm{D}$ analyses 


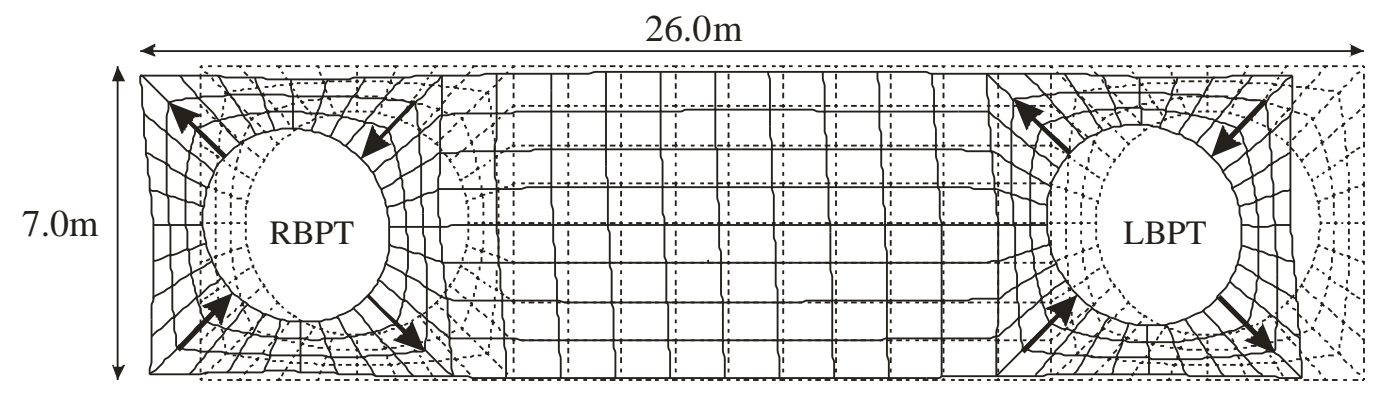

Deformation scale:

Figure 11: Enlarged view of the deformed mesh at $\mathrm{t}=8.0 \mathrm{sec}$

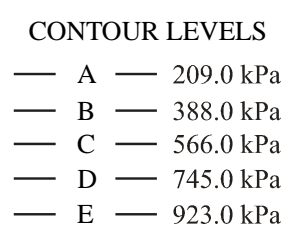

(a) $\mathrm{t}=5.0 \mathrm{sec}$

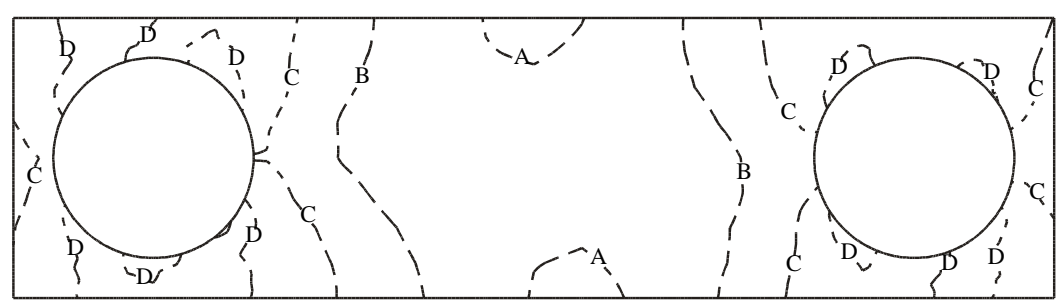

CONTOUR LEVELS

$-\mathrm{A}-146.0 \mathrm{kPa}$

$-\mathrm{B}-329.0 \mathrm{kPa}$

$-\mathrm{C}-512.0 \mathrm{kPa}$

$-\mathrm{D}-695.0 \mathrm{kPa}$

$-\mathrm{E}-875.0 \mathrm{kPa}$

(b) $\mathrm{t}=6.0 \mathrm{sec}$

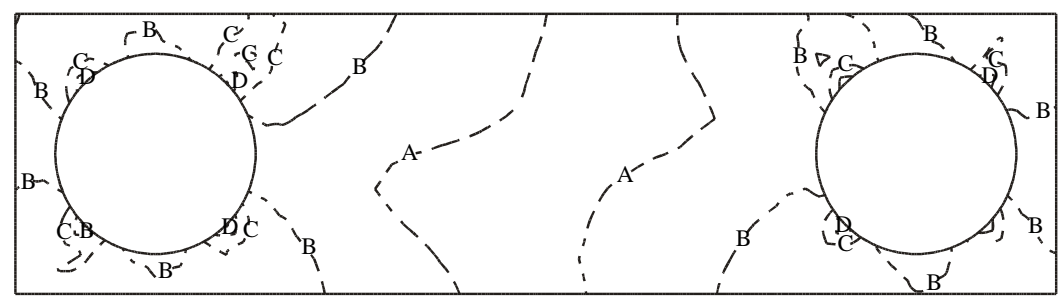

CONTOUR LEVELS

- $\mathrm{A}-91.6 \mathrm{kPa}$

$-\mathrm{B}-313.0 \mathrm{kPa}$

$-\mathrm{C}-535.0 \mathrm{kPa}$

$-\mathrm{D}-757.0 \mathrm{kPa}$

$-\mathrm{E}-978.0 \mathrm{kPa}$

(c) $\mathrm{t}=7.0 \mathrm{sec}$

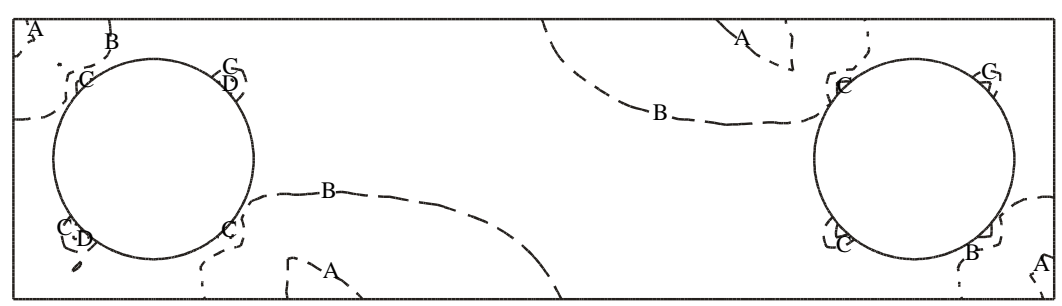

CONTOUR LEVELS

- $\mathrm{A}-73.5 \mathrm{kPa}$

$-\mathrm{B}-284.0 \mathrm{kPa}$

$-\mathrm{C}-495.0 \mathrm{kPa}$

$-\mathrm{D}-706.0 \mathrm{kPa}$

$-\mathrm{E}-916.0 \mathrm{kPa}$

(d) $\mathrm{t}=8.0 \mathrm{sec}$

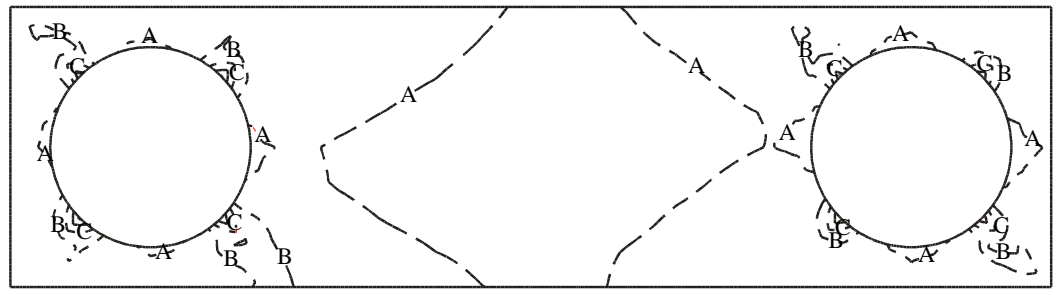

Figure 12: Contours of deviatoric stress ( $\mathrm{J})$ (at $\mathrm{t}=5.0,6.0,7.0$ and 8.0sec) in the vicinity of the tunnels (for the area indicated in Figure 11) 

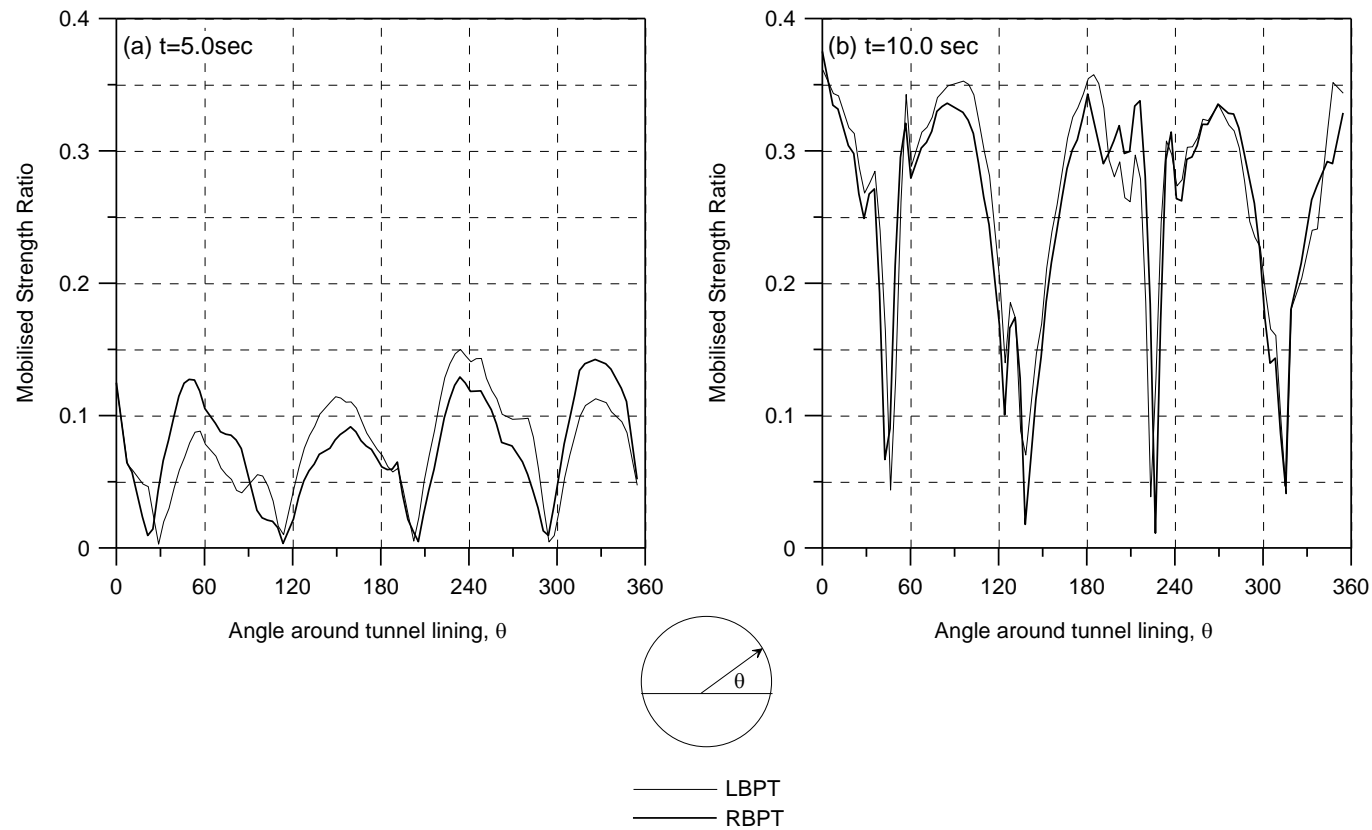

Figure 13: Mobilised strength ratio along BPTs' lining at $t=5 \mathrm{sec}$ (a) and at $\mathrm{t}=10 \mathrm{sec}$
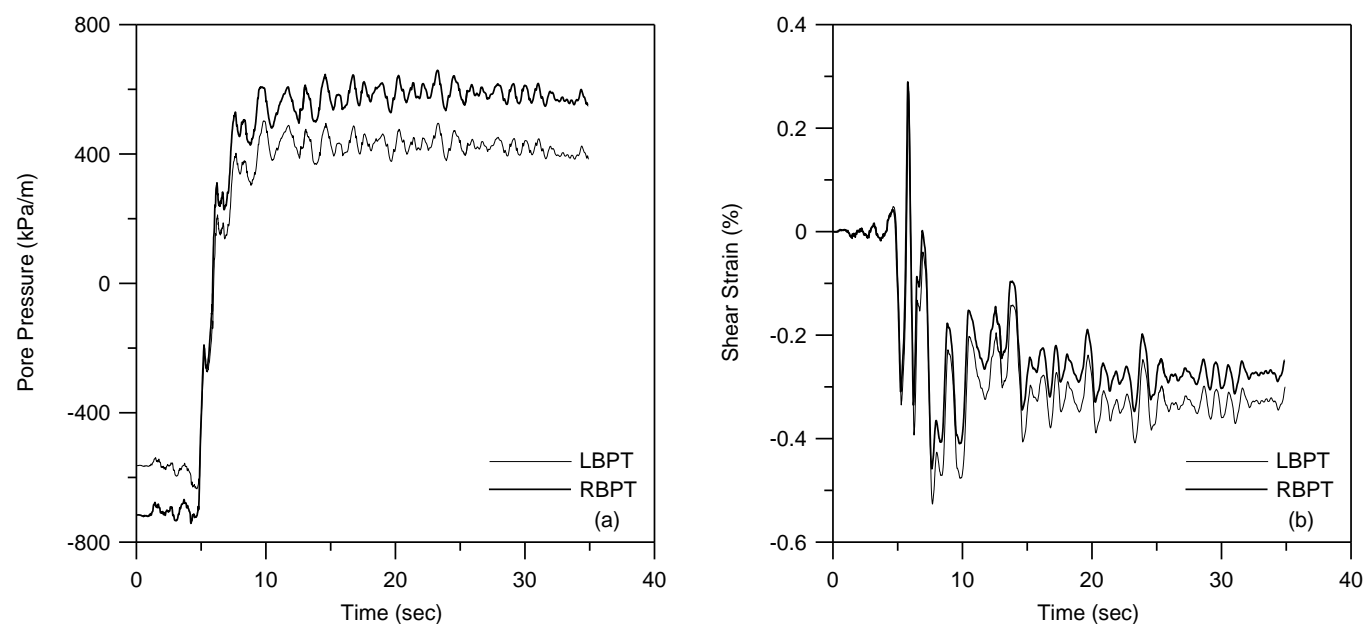
Figure 14: Pore water pressure (a) and shear strain (b) time histories for integration points adjacent to the crowns of the BPTs
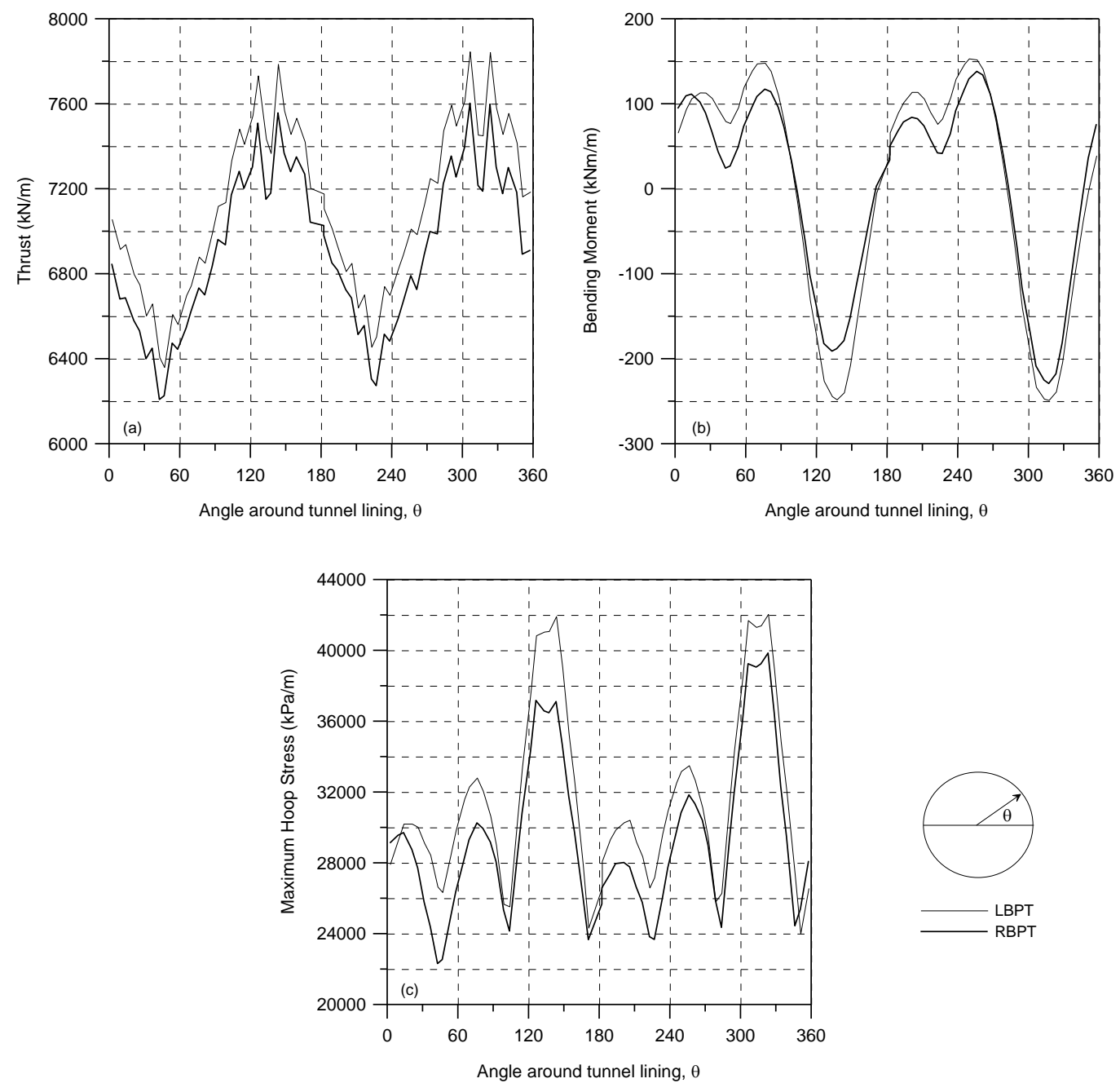

Figure 15: Accumulated thrust (a), bending moment (b) and maximum hoop stress (c) distribution around the tunnels' lining at $\mathrm{t}=10.0 \mathrm{sec}$
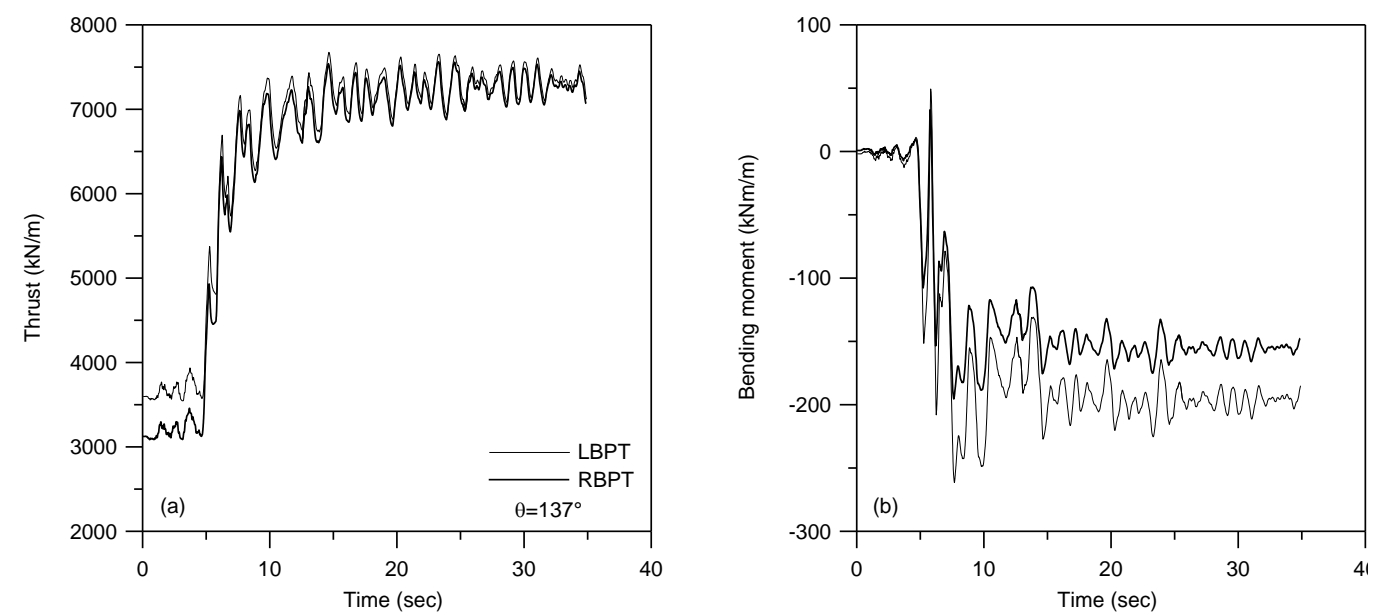
Figure 16: Thrust (a) and bending moment (b) time histories at $\theta=137^{\circ}$ for both BPTs
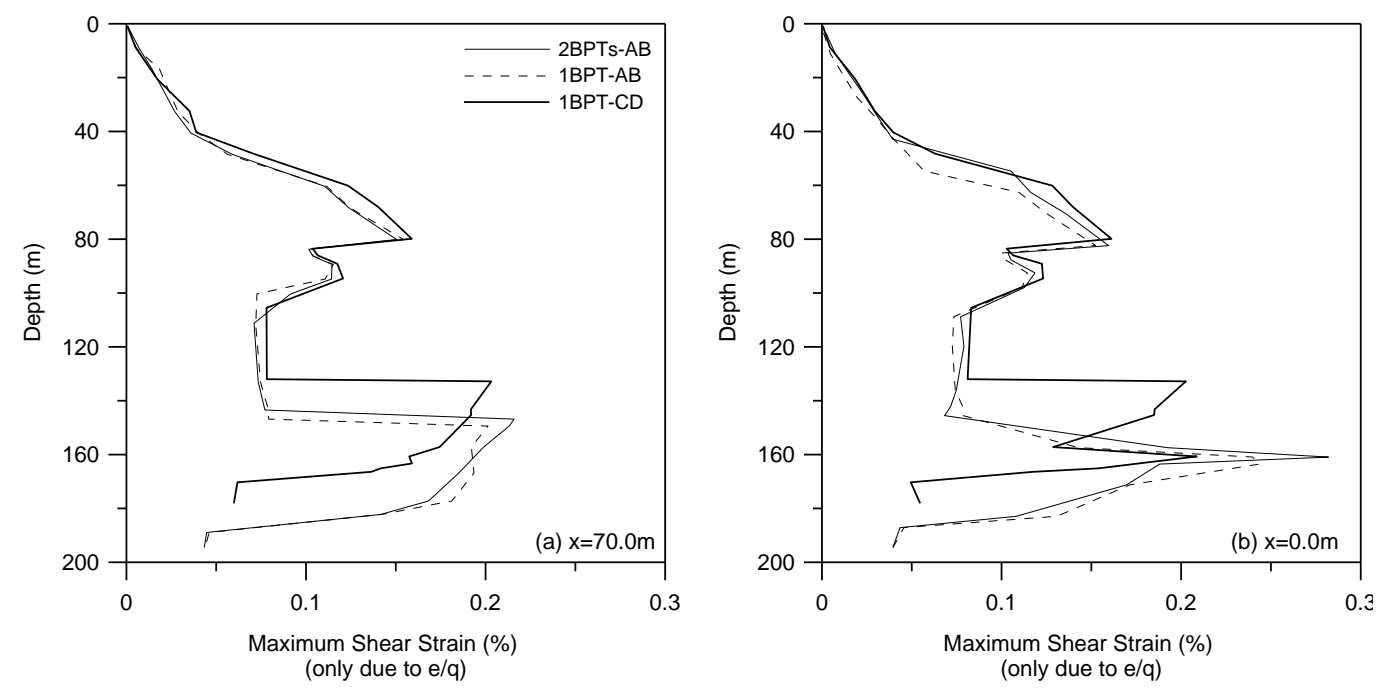

Figure 17: Maximum shear strain profile computed with the 2BPTs-AB, the 1BPT-

$\mathrm{AB}$ and the 1BPT-CD model at $\mathrm{x}=70.0 \mathrm{~m}$ (a) and at $\mathrm{x}=0.0 \mathrm{~m}$ (b)
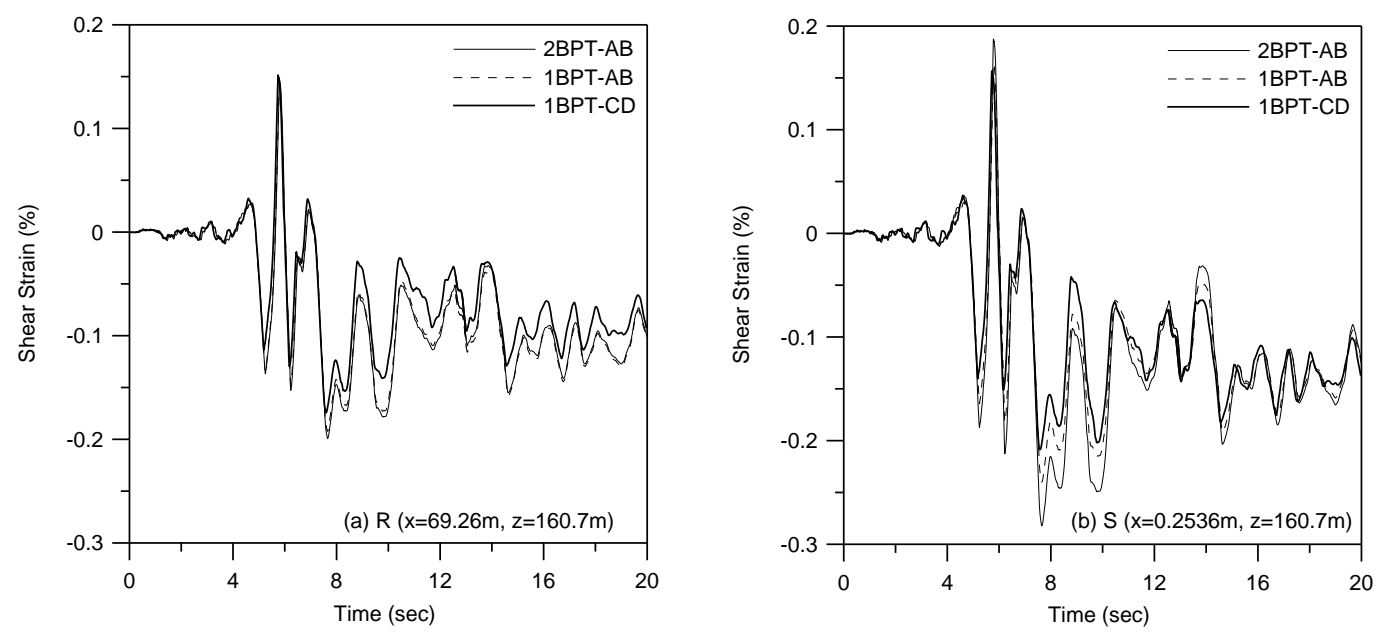

Figure 18: Shear strain time histories computed with the 2BPTs-AB, the 1BPT-AB and the 1BPT-CD model at integration points $\mathrm{R}$ and $\mathrm{S}$

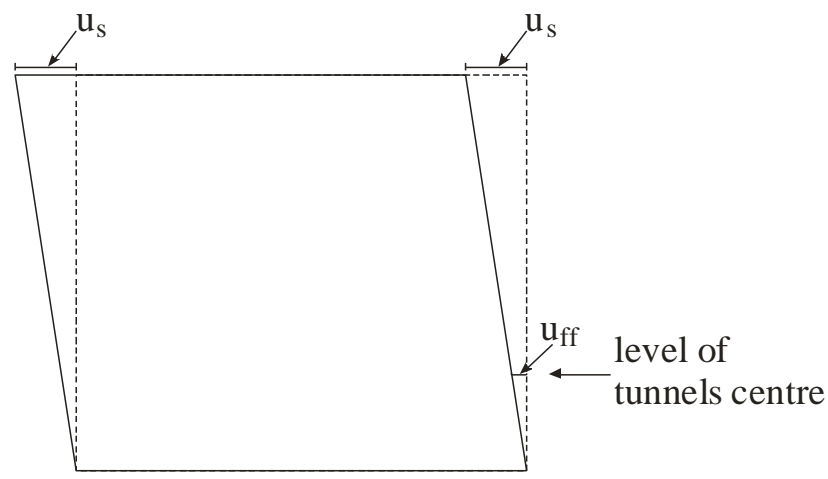

Figure 19: Schematic representation of FE mesh configuration in quasi-static analysis 

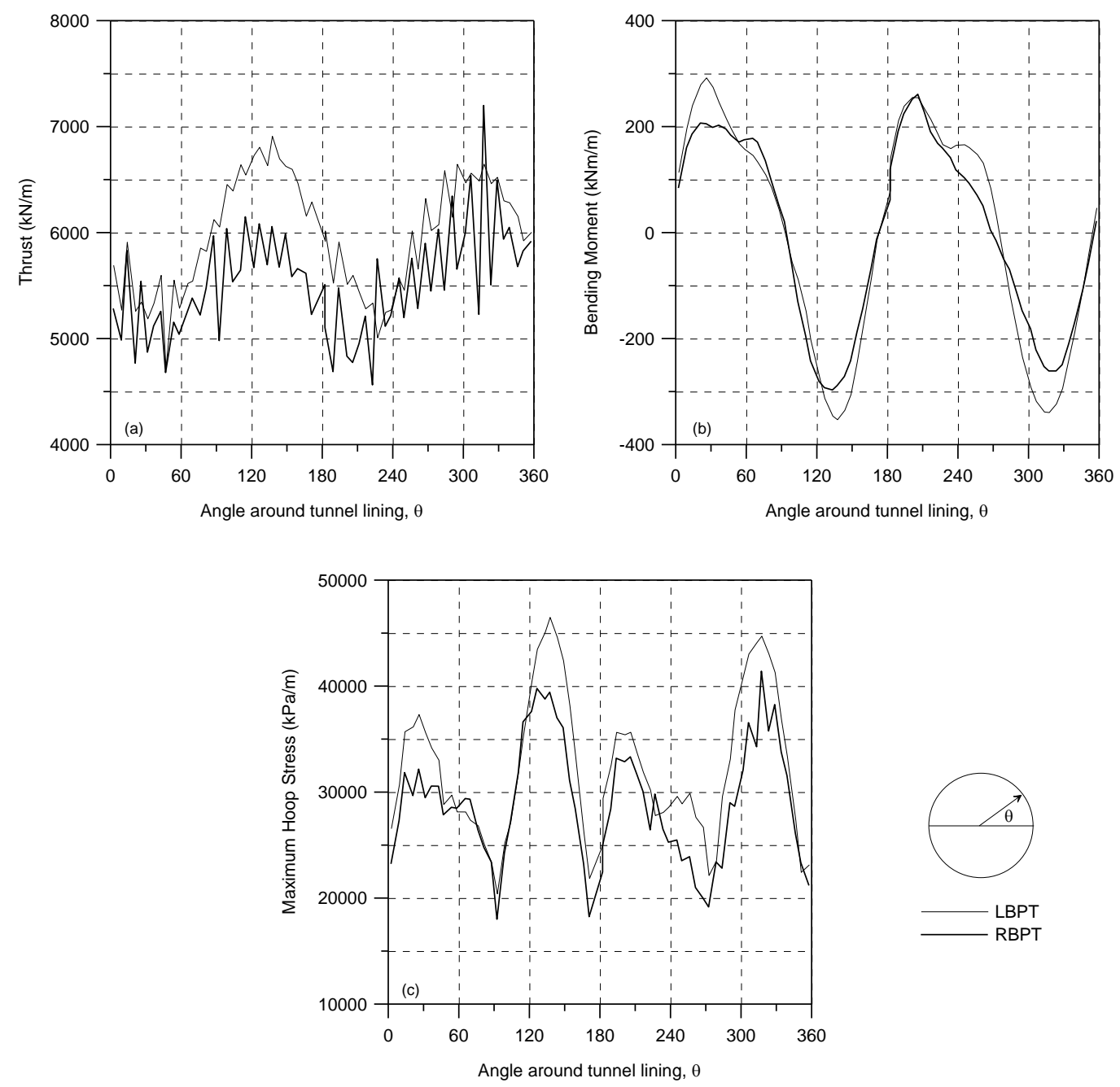

Figure 20: Accumulated thrust (a), bending moment (b) and maximum hoop stress (c) distribution around the tunnels' lining at the end of the quasi-static analysis
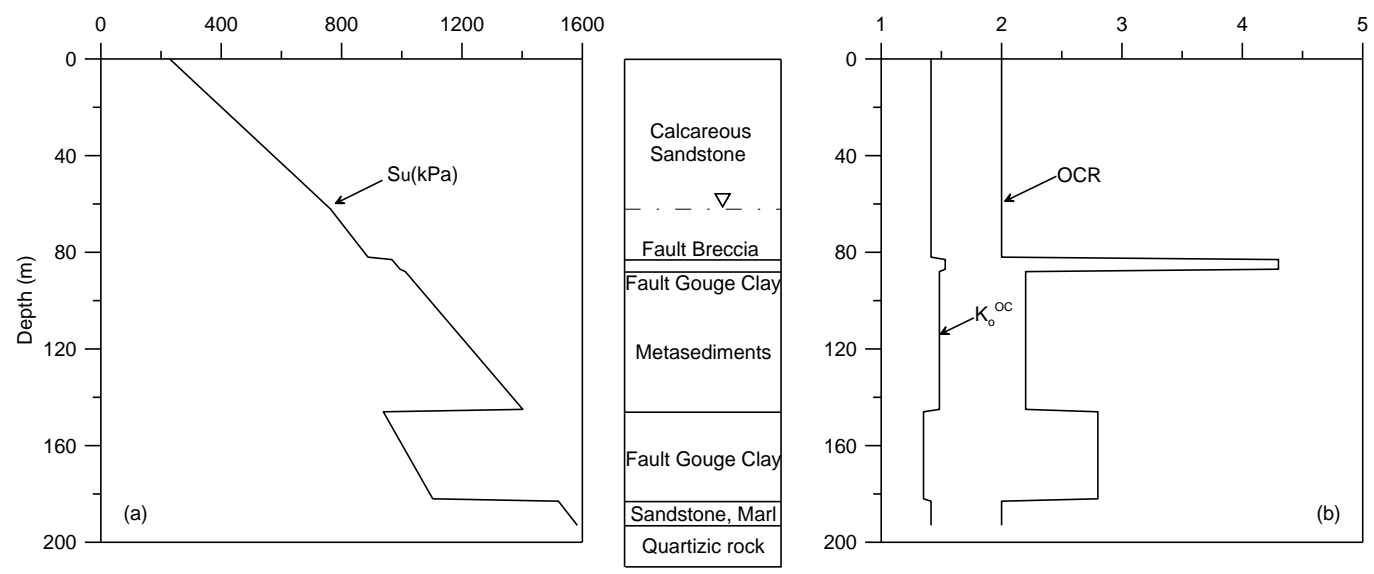

Figure A.1: Undrained strength (Su) (a), overconsolidation ratio (OCR) and coefficient of earth pressure at rest $\left(\mathrm{K}_{\mathrm{O}}^{\mathrm{OC}}\right)(\mathrm{b})$ profiles. 


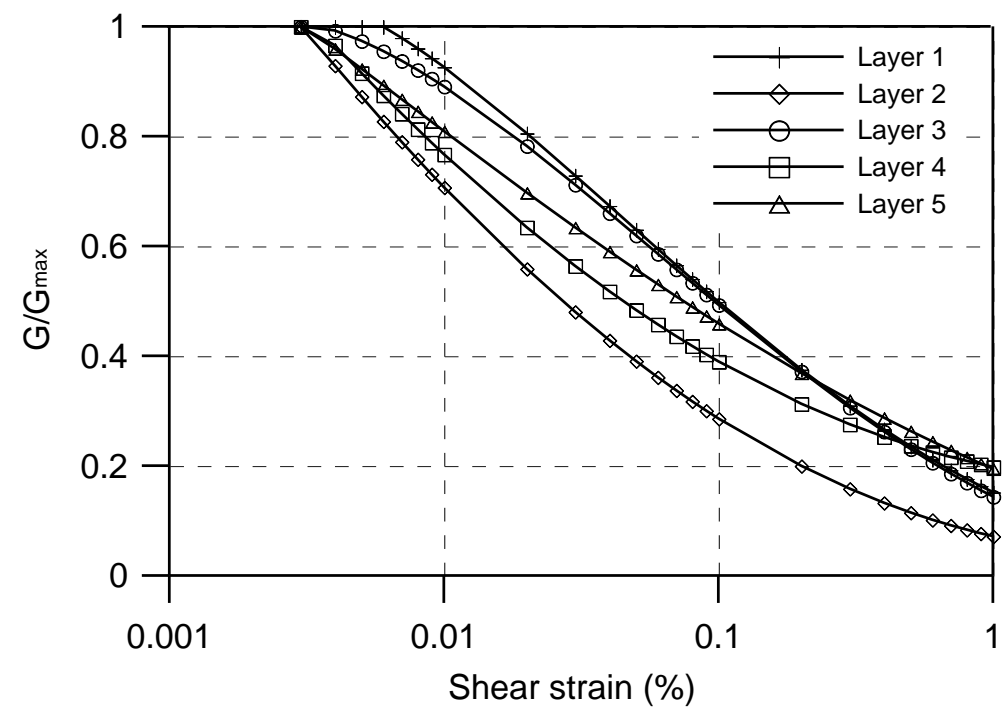

Figure A.2: Shear stiffness-strain curves of different materials used in equivalent linear analyses

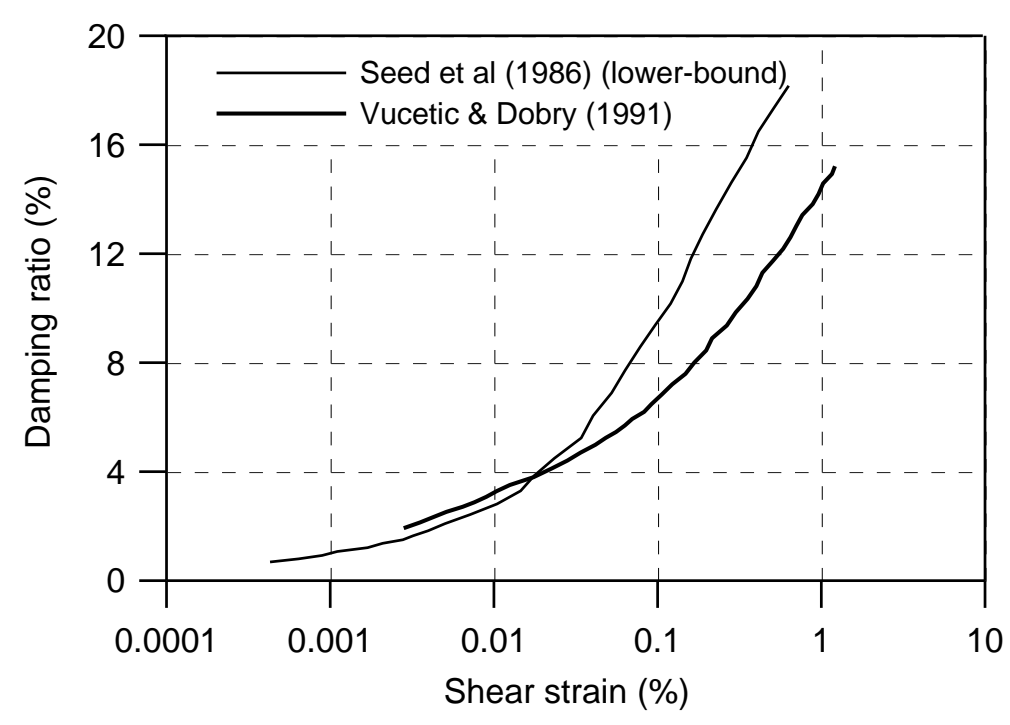

Figure A.3: Damping ratio-shear strain curves used in equivalent linear analyses 


\subsection{Tables}

Table 1: Geotechnical description and index properties

\begin{tabular}{|c|c|c|c|}
\hline Unit & Consistency & PI (\%) & $\begin{array}{c}\mathrm{CP}^{4}(\%) \& \\
\text { Mineralogy }\end{array}$ \\
\hline $\begin{array}{c}\text { Calcareous } \\
\text { sandstone }\end{array}$ & $\begin{array}{c}\text { Brown coloured slightly to } \\
\text { highly weathered/ fractured. }\end{array}$ & $?$ & $?$ \\
\hline $\begin{array}{c}\text { Fault breccia } \\
\text { and fault } \\
\text { gouge clay }\end{array}$ & $\begin{array}{c}\text { heavily slicken-sided, highly } \\
\text { plastic, stiff to hard fault gouge }\end{array}$ & 55 & $30-60$ \\
\hline $\begin{array}{c}\text { Metasediments } \\
\text { Gravel, cobble and boulder } \\
\text { sized shear bodies in soil matrix. }\end{array}$ & $10-15$ & $\begin{array}{c}5-25 ; \text { illite } \\
(58 \%), \\
\text { smectite }\end{array}$ \\
\hline $\begin{array}{c}\text { Fault gouge } \\
\text { clay }\end{array}$ & $\begin{array}{c}\text { Red to brown coloured, heavily } \\
\text { slicken-sided, highly plastic, } \\
\text { stiff to hard fault gouge }\end{array}$ & $40-60$ & $\begin{array}{c}20-50, \\
\text { smectite }\end{array}$ \\
\hline $\begin{array}{c}\text { Sandstone, } \\
\text { siltstone with } \\
\text { marl fragments }\end{array}$ & $\begin{array}{c}\text { Gray sandstone with green, } \\
\text { weathered, medium strong to } \\
\text { weak marl fragments. }\end{array}$ & 15 & $0-20$ \\
\hline Bedrock & $\begin{array}{c}\text { Strong to very strong, faulted- } \\
\text { fractured quarzitic rock. }\end{array}$ & $?$ & $?$ \\
\hline
\end{tabular}

${ }^{4}$ Clay percentage by weight. 
Table 2: Estimated strength and stiffness parameters

\begin{tabular}{|c|l|l|l|l|l|l|}
\hline \multirow{2}{*}{ Unit } & \multicolumn{2}{|l|}{$\varphi^{\prime}$} & \multicolumn{2}{l|}{$\mathrm{c}^{\prime}(\mathrm{kPa})$} & \multirow{2}{*}{$\mathrm{Su}$} & $\mathrm{G}_{\max }$ \\
\cline { 2 - 7 } & peak & residual & peak & residual & $(\mathrm{kPa})$ & $(\mathrm{MPa})$ \\
\hline $\begin{array}{c}\text { Calcareous } \\
\text { sandstone }\end{array}$ & $25^{\circ}-30^{\circ}$ & $20^{\circ}-25^{\circ}$ & 50 & 25 & 700 & 1000 \\
\hline $\begin{array}{c}\text { Fault breccia } \\
\text { and fault gouge } \\
\text { clay }\end{array}$ & $13^{\circ}-16^{\circ}$ & $9^{\circ}-12^{\circ}$ & 100 & 50 & 1000 & 750 \\
\hline $\begin{array}{c}\text { Metasediments } \\
\text { Fault gouge clay }\end{array}$ & $25^{\circ}-30^{\circ}-24^{\circ}$ & $20^{\circ}-25^{\circ}-12^{\circ}$ & 50 & 25 & 1350 & 1500 \\
\hline $\begin{array}{c}\text { Sandstone, } \\
\text { siltstone with } \\
\text { marl fragments }\end{array}$ & $25^{\circ}-30^{\circ}$ & $20^{\circ}-25^{\circ}$ & 50 & 25 & 1500 & 2500 \\
\hline
\end{tabular}

Table 3: Strength properties of the BPTs at the time of earthquake at chainage $62+850$

\begin{tabular}{|c|c|}
\hline \multicolumn{2}{|c|}{$\begin{array}{c}\text { Cube Strength } \\
\text { (fcu, MPa) }\end{array}$} \\
\hline LBPT & RBPT \\
(shotcrete15 days old ) & (shotcrete 7 days old ) \\
\hline 40 & 30 \\
\hline
\end{tabular}


Table 4: Stiffness properties of the BPTs just after construction and at the time of the earthquake

\begin{tabular}{|c|c|c|c|c|}
\hline & \multicolumn{2}{|c|}{ LBPT } & \multicolumn{2}{c|}{ RBPT } \\
\hline Age of shotcrete & 1 day & 15 days & 1 day & 7 days \\
\hline $\begin{array}{c}\text { Increment number } \\
\text { Young's Modulus } \\
(\mathrm{GPa})\end{array}$ & 5 & 11 & 6 & 11 \\
\hline
\end{tabular}

Table 5: Geometrical and material properties of tunnel linings

\begin{tabular}{|c|c|c|c|c|c|c|}
\hline & $\begin{array}{c}\mathrm{t} \\
(\mathrm{m})\end{array}$ & $\begin{array}{c}\mathrm{I} \\
\left(\mathrm{m}^{4} / \mathrm{m}\right)\end{array}$ & $v_{1}$ & $\begin{array}{c}\rho \\
\left(\mathrm{Mg} / \mathrm{m}^{3}\right)\end{array}$ & $\mathrm{C}$ & $\mathrm{F}$ \\
\hline LBPT & 0.3 & 0.00225 & 0.2 & 2.45 & 1.21 & 67.46 \\
\hline RBPT & 0.3 & 0.00225 & 0.2 & 2.45 & 1.62 & 89.95 \\
\hline
\end{tabular}

Table 6: Summary of the diametral movements and strains after the static analysis

\begin{tabular}{|c|c|c|c|c|}
\hline \multirow{2}{*}{$\begin{array}{c}\text { Diametral } \\
\text { Convergence }\end{array}$} & \multicolumn{2}{|c|}{ LBPT } & \multicolumn{2}{c|}{ RBPT } \\
\cline { 2 - 5 } & $(\mathrm{mm})$ & $(\%)$ & $(\mathrm{mm})$ & $(\%)$ \\
\hline Horizontal & 40.72 & 0.81 & 51.86 & 1.03 \\
\hline Vertical & 28.59 & 0.57 & 37.88 & 0.76 \\
\hline
\end{tabular}


Table 7: Maximum hoop stress at shoulder and knee locations of the BPTs' lining computed with the M2-SKH model

\begin{tabular}{|c|c|c|c|}
\hline \multirow{2}{*}{ Point } & \multicolumn{3}{|c|}{ Maximum Hoop Stress $\left(\sigma_{\mathrm{H}}\right)(\mathrm{MPa})$} \\
\cline { 2 - 4 } & Static & Earthquake & Total \\
\hline LBPT, $\theta=137^{\circ}$ & 12.1 & 29.2 & 41.3 \\
\hline LBPT, $\theta=317^{\circ}$ & 12.5 & 29.0 & 41.5 \\
\hline RBPT, $\theta=137^{\circ}$ & 10.5 & 26.4 & 36.9 \\
\hline RBPT, $\theta=317^{\circ}$ & 10.5 & 29.6 & 40.1 \\
\hline
\end{tabular}

Table 8: Maximum hoop stress developed at the LBPT for various analyses

\begin{tabular}{|c|c|c|c|}
\hline \multirow{2}{*}{ Analysis } & \multicolumn{3}{|c|}{ Maximum Hoop Stress $\left(\sigma_{\mathrm{H}}\right)(\mathrm{MPa})$} \\
\cline { 2 - 4 } & Static & Earthquake & Total \\
\hline 2BPTs-AB & 12.5 & 29.0 & 41.5 \\
\hline 1BPT-AB & 12.2 & 29.1 & 41.3 \\
\hline 1BPT-CD & 10.3 & 26.9 & 37.2 \\
\hline
\end{tabular}

Table 9: Analytical methods parameters

\begin{tabular}{|c|c|c|c|}
\hline Parameter & Soil (layer 4) & LBPT & RBPT \\
\hline $\mathrm{E}_{\mathrm{m}}(\mathrm{kPa})$ & $2.21 \times 10^{6}$ & - & - \\
\hline$v_{\mathrm{m}}$ & 0.3 & - & - \\
\hline $\mathrm{E}_{1}(\mathrm{kPa})$ & - & $28.0 \times 10^{6}$ & $21.0 \times 10^{6}$ \\
\hline$v_{1}$ & - & 0.2 & 0.2 \\
\hline $\mathrm{t}(\mathrm{m})$ & - & 0.3 & 0.3 \\
\hline $\mathrm{I}\left(\mathrm{m}^{4} / \mathrm{m}\right)$ & - & 0.00225 & 0.00225 \\
\hline
\end{tabular}




\begin{tabular}{|c|c|c|c|}
\hline $\mathrm{r}(\mathrm{m})$ & - & 5.0 & 5.0 \\
\hline
\end{tabular}

Table 10: Summary of analytical results for the LBPT

\begin{tabular}{|c|c|c|c|c|}
\hline \multirow{2}{*}{ LBPT } & \multicolumn{2}{|c|}{ Extended Hoeg } & \multicolumn{2}{c|}{ Penzien (2000) } \\
\cline { 2 - 5 } & Full Slip & No Slip & Full Slip & No Slip \\
\hline $\mathrm{T}_{\max }(\mathrm{kN} / \mathrm{m})$ & 81.8 & 3959.2 & 81.9 & 163.2 \\
\hline $\mathrm{M}_{\max }(\mathrm{kNm} / \mathrm{m})$ & 204.6 & 204.6 & 204.6 & 204.0 \\
\hline$\sigma_{\mathrm{H} \max }(\mathrm{MPa})$ & 13.9 & 26.8 & 13.9 & 14.15 \\
\hline
\end{tabular}

Table 11: Summary of analytical results for the RBPT

\begin{tabular}{|c|c|c|c|c|}
\hline \multirow{2}{*}{ RBPT } & \multicolumn{2}{|c|}{ Extended Hoeg } & \multicolumn{2}{c|}{ Penzien (2000) } \\
\cline { 2 - 5 } & Full Slip & No Slip & Full Slip & No Slip \\
\hline $\mathrm{T}_{\max }(\mathrm{kN} / \mathrm{m})$ & 61.7 & 3742.7 & 61.7 & 123.2 \\
\hline $\mathrm{M}_{\max }(\mathrm{kNm} / \mathrm{m})$ & 154.4 & 154.4 & 154.4 & 154.0 \\
\hline$\sigma_{\mathrm{H} \max }(\mathrm{MPa})$ & 10.5 & 22.8 & 10.5 & 10.7 \\
\hline
\end{tabular}

Table A1: Material properties used for M2-SKH model

\begin{tabular}{l|lllll}
\hline Layer & $\lambda$ & $\kappa$ & $\mathrm{v}_{1}$ & $\mathrm{G}$ & $\varphi^{\prime}$ \\
\hline 1 & 0.2 & 0.02 & 3.2 & 1000.0 & $30^{\circ}$ \\
2 & 0.2 & 0.02 & 4.5 & 750.0 & $17^{\circ}$ \\
3 & 0.2 & 0.02 & 3.2 & 1500.0 & $30^{\circ}$ \\
4 & 0.2 & 0.02 & 4.5 & 850.0 & $17^{\circ}$ \\
5 & 0.2 & 0.02 & 3.2 & 2500.0 & $30^{\circ}$ \\
\hline
\end{tabular}




\subsection{Appendix}

\subsubsection{Selection of M2-SKH model parameters}

Five of the parameters required by the M2-SKH model have their origin in the Modified Cam Clay (MCC) model. These are: three compression parameters (the slope of the virgin compression line $\lambda$, the slope of the swelling line $\kappa$ and the specific volume at unit pressure $\mathrm{v}_{1}$ on the virgin compression line), one drained strength parameter $\left(\varphi^{\prime}\right)$ and one elastic parameter (the maximum shear modulus $G$ ). The values of these parameters for the different layers are listed in Table A1. In the absence of oedometer test data, typical values of compression parameters for stiff clays/ soft rocks were chosen. Furthermore, the selected values of $\varphi^{\prime}$ are based both on the peak strength variation of Table 2 and on geotechnical in-situ description of the different units for the relevant cross-sections. Moreover, Potts and Zdravković, (1999) showed that the above-mentioned input parameters of the MCC model and the initial state of stress can be directly related to the undrained strength $S_{\mathrm{u}}$, as follows:

$$
\frac{\mathrm{S}_{\mathrm{u}}}{\sigma_{\mathrm{vi}}^{\prime}}=\mathrm{g}(\theta) \cos (\theta) \frac{\mathrm{OCR}}{6}\left(1+2 \mathrm{~K}_{\mathrm{O}}^{\mathrm{NC}}\right)\left[1+\mathrm{B}^{2}\right]\left[\frac{2\left(1+2 \mathrm{~K}_{\mathrm{O}}^{\mathrm{OC}}\right)}{\left(1+2 \mathrm{~K}_{\mathrm{O}}^{\mathrm{NC}}\right) \mathrm{OCR}\left[1+\mathrm{B}^{2}\right]}\right]^{\frac{\mathrm{K}}{\lambda}}
$$

where $\sigma_{\mathrm{vi}}^{\prime}$ is the initial vertical effective stress, $\mathrm{g}(\theta)$ is a function defining the shape of the yield surface in the deviatoric plane, $\mathrm{K}_{\mathrm{O}}^{\mathrm{NC}}$ is the value of the coefficient of earth pressure at rest associated with normal consolidation, $\mathrm{K}_{\mathrm{O}}^{\mathrm{OC}}$ is the current value of the coefficient of earth pressure at rest, $\theta$ is the Lode's angle, OCR is the overconsolidation ratio defined as: $\mathrm{OCR}=\frac{\sigma_{\mathrm{vm}}^{\prime}}{\sigma_{\mathrm{vi}}^{\prime}}$, where $\sigma_{\mathrm{vm}}^{\prime}$ is the maximum vertical effective stress that the soil has been subjected to and B is defined as:

$$
\mathrm{B}=\frac{\sqrt{3}\left(1-\mathrm{K}_{\mathrm{o}}^{\mathrm{NC}}\right)}{\mathrm{g}\left(-30^{\circ}\right)\left(1+2 \mathrm{~K}_{\mathrm{o}}^{\mathrm{NC}}\right)}
$$

The estimated undrained strength for each layer is listed in Table 2. Employing Equation [A.1] and the input parameters listed in Table A1 the initial stress state 
parameters $\left(\mathrm{OCR}, \mathrm{K}_{\mathrm{o}}\right)$ can be selected to match the undrained strength values of Table 2 for the middle of each layer (assuming that the undrained strength varies linearly with depth in each layer). Figure A.1 plots the assumed variation of Su with depth and the resulting OCR and $\mathrm{K}_{\mathrm{O}}^{\mathrm{OC}}$ profiles. It should also be noted that a linear variation of suction is assumed above the water table.

The remaining 2 parameters $\left(\mathrm{R}_{\mathrm{b}}, \alpha\right)$ of the M2-SKH model define the behaviour of the kinematic surface. To derive reliable values for the parameter $R_{b}$ (i.e. the ratio of the size of the bubble to that of the bounding surface), test data with measurements of strains in the very small and small strain region are required. Since no such data are available, the $R_{b}$ is assumed to be 0.1 for the two clays and 0.15 for the soft rock layers. Furthermore, the parameter $\alpha$, which controls the decay of stiffness, cannot be measured directly from the experimental data and is usually determined by trial and error. However due to lack of data, a value of $\alpha$ equal to 15.0 was adopted for all layers based on Grammatikopoulou (2004).

\subsubsection{Selection of equivalent linear elastic model parameters}

Figure A.2 illustrates the shear stiffness degradation curves that were used for each layer in the equivalent linear analyses. The shear stiffness variations of the clays and metasediments were matched to data from pressuremeter tests. Since there was no information available regarding the shear stiffness degradation of the sandstones (i.e. layers 1 and 5), the two sandstones were assumed to have similar shear stiffness degradation as the metasediments (i.e. layer 3). In addition the damping ratio curves of Vucetic and Dobry (1991) for overconsolidated clays with a plasticity index of 50 were adopted for the two clay layers while for the remaining rock strata the lower limit of the Seed et al's (1986) range of damping ratio curves for sands was employed (Figure A.3). 